\title{
Protein-free formation of bone-like apatite: New insights into the key role of carbonation
}

Alix C. Deymier ${ }^{1}$, Arun K. Nair ${ }^{2}$, Baptiste Depalle ${ }^{3}$, Zhao Qin ${ }^{4}$, Kashyap $\operatorname{Arcot}^{5}$, Christophe Drouet ${ }^{6}$, Claude H. Yoder $^{7}$, Markus J. Buehler ${ }^{4}$, Stavros Thomopoulos ${ }^{1}$, Guy M. Genin ${ }^{5}$, Jill D. Pasteris ${ }^{8}$

1. Dept. of Orthopedic Surgery, Columbia University, New York, NY, 10032

2. Dept. of Mechanical Engineering, University of Arkansas, Fayetteville, AR, 72701

3. Dept. of Materials, Imperial College, London, SW7 2AZ - UK

4. Dept. of Civil and Environmental Engineering, MIT, Boston, MA 02139

5. Dept. of Mechanical Engineering and Materials Science, Washington University, St. Louis, MO, 63130

6. CIRIMAT, Université de Toulouse, CNRS/UPS/INP, Ensiacet, Toulouse, 31030 France

7. Dept. of Chemistry, Franklin and Marshall College, Lancaster, PA, 17604

8. Dept. of Earth and Planetary Sciences, Washington University, St Louis, MO, 63130

Corresponding Authors:

Stavros Thomopoulos

Orthopedic Surgery

Columbia University

$650 \mathrm{~W} 168 \mathrm{St}$

New York, NY 10032

sat2@cumc.columbia.edu

(917) 287-9819

Jill Pasteris

Department of Earth and Planetary Sciences

Washington University in St Louis

1 Brookings Dr

Saint Louis MO 63130

pasteris@levee.wustl.edu

(314) 935-5434

Alix Deymier

Department of Orthopedic Surgery

Columbia University

$650 \mathrm{~W} 168^{\text {th }} \mathrm{St}$

New York, NY 10032

Alix.c.deymier@gmail.com

(520) 248-1956

Keywords: biomineralization, carbonate, substitution, calcium phosphate, bone

Abstract

The nanometer-sized plate-like morphology of bone mineral is necessary for proper bone mechanics and physiology. However, mechanisms regulating the morphology of these mineral nanocrystals remain unclear. The dominant hypothesis attributes the size and shape regulation to organic-mineral interactions. Here, we present data supporting the hypothesis that physicochemical effects of carbonate integration within the apatite lattice control the morphology, size, and mechanics of bioapatite mineral crystals. Carbonated apatites synthesized in the absence of organic molecules presented plate-like morphologies and nanoscale crystallite dimensions. Experimentally-determined crystallite size, lattice spacing, solubility and atomic order were modified by carbonate concentration. Molecular dynamics (MD) simulations and density functional theory (DFT) calculations predicted changes in surface energy and elastic moduli with carbonate concentration. Combining these results with a scaling law predicted the experimentally observed scaling of size and energetics with carbonate concentration. The experiments and models describe a clear mechanism by which crystal dimensions are controlled by carbonate substitution. Furthermore, the results demonstrate that carbonate substitution is sufficient to drive the formation of bone-like crystallites. This new understanding points to pathways for biomimetic synthesis of novel, nanostructured biomaterials.

(C) 2017. This manuscript version is made available under the Elsevier user license http://www.elsevier.com/open-access/userlicense/1.0/ 
Bone is a composite material composed of the protein type I collagen and plate-like nanocrystals of mineral. The nanometer scale of the mineral crystallites has been shown to be essential to proper bone function and physiology. The nano-size allows the crystallites to be flaw intolerant, thereby optimizing the fracture strength of the bone.[1] In addition, the large surface area of the nano-plates increases the dissolution rate, which allows the body to quickly release necessary ions in response to pathologies such as acidosis.[2-4] Although the nanocrystal size and morphology are essential to bone's mechanical and physiological functions and must be considered in the creation of bone replacement biomaterials, the mechanism by which these properties are controlled remains unclear.

The mineral phase in bone is often described as hydroxylapatite, a natural geologically occurring $\mathrm{OH}^{-}$containing calcium apatite. Geological hydroxylapatite forms large hexagonal prisms that derive from its hexagonal lattice structure.[5] However, the mineral in bone resembles nanometer-scale elongated plates or blades while still maintaining an internal hexagonal lattice structure.[6-12] More precisely, the nanocrystals of both bone and biomimetic apatites exhibit a complex substructure composed of (1) an apatitic, often nonstoichiometric core containing ions in apatitic (i.e., lattice) chemical environments and (2) a surface layer containing ions in non-apatitic (i.e., non-lattice) environments and surrounded by water molecules.[13] In order to explain this discrepancy between the morphology of geological (inorganic) and biological apatites, many researchers have suggested that bone's crystallite size and shape are controlled via templating by or chemical interactions with surrounding proteins and organic moieties. $[10-12,14,15]$ It has been theorized that the fibrillar structure of collagen dictates the size of the crystallites via physical confinement within its nanometer-sized gap zones.[12,16] Others propose that proteins or other organic moieties bind to the mineral surface and control crystal growth.[10, 11, $14,15,17]$ These results seem to suggest that organic interactions are necessary for the formation of plate-like nanocrystals. However, what many of these studies fail to consider is the true composition of bioapatite.

The apatite structure is remarkably accommodating to substitutions. [18] The most common substitutions seen in bone mineral are the coupled substitution of $\mathrm{CO}_{3}{ }^{2-}$ for $\mathrm{PO}_{4}{ }^{3-}$ and $\mathrm{Na}^{+}$for $\mathrm{Ca}^{2+}$, which lead to vacancies on the calcium and hydroxyl sites. [18-20] As a result, bone mineral is more accurately described as a carbonated, calcium- and hydroxyl-depleted apatite. The substitution of carbonate into the apatite structure can occur at one or both of two sites: in exchange for hydroxyl $\left(\mathrm{OH}^{-}\right)$, defined as Atype, or for phosphate $\left(\mathrm{PO}_{4}{ }^{3-}\right)$, defined as B-type.[21] In mammalian bone, carbonate levels span 2-8 $w t \%$, depending on species and bone location, and are predominantly of B-type substitution. [18, 22-24] Empirical observations have qualitatively shown that carbonate content in the apatite lattice affects crystallite size [25-29], solubility [8, 30,31], and crystal mechanics [32]. These results suggest that, in addition to possible organic interactions, carbonate concentration plays an essential role in regulating bone mineral morphology. Despite the importance of carbonate substitution on crystal properties, there is no proposed mechanism for this process. We hypothesized that, in the absence of proteins or other organic substances, carbonate substitution, through its control of crystal lattice spacing, atomic order, and solubility, is sufficient to control apatite crystals' nano-scale size, shape, and mechanics via energetic effects $[8,26,30,31]$. This work proposes, for the first time, a direct mechanism for substitutional effects on crystallite morphology. 
A protein-free solution precipitation technique was used to prepare biomimetic apatites with carbonate concentrations ranging from 1.0 - 17.8 wt\%. The composition, gross morphology, and lattice structure were measured experimentally, providing a comprehensive analysis of biomimetic carbonated apatites. Molecular dynamics (MD) and density functional theory (DFT) calculations, which were validated through comparison to experimental results, evaluated the energetics (i.e., conservation of energy and a trade-off between surface energy and strain energy) of carbonate substitution. This work presents a situation where nanoparticles are not created via templating to enhance the chemical properties but in which the chemistry itself imposes a nanoscopic size. Organic templating is not necessary to form crystallites that exhibit physiological structures; rather, control of carbonate substitution is sufficient to precipitate crystallites with the correct nanometer-scale size and morphology. Experimental and theoretical parameters from these analyses were used in a continuum analysis to derive a proposed mechanism for how carbonate substitution controls crystallite size. Understanding this relationship provides new insight into the formation of biomimetic crystals for tissue engineering.

\section{Methods}

Synthesis of Powders

Apatite powders were made according to previously described methods [33-35] and summarized here. All water used in the synthesis was either deionized water further purified by passing through a calcium hydroxylapatite column or doubly deionized Milli-Q (18 $\mathrm{M} \Omega$ ) water in order to minimize the amount of fluoride present. Nitrogen was then bubbled through the water for several hours in order to remove dissolved carbon dioxide. Approximately $250 \mathrm{~mL}$ of water was placed in a large beaker and heated to the desired reaction temperature (usually $60^{\circ} \mathrm{C}$ or $85^{\circ} \mathrm{C}$ ). Mixtures were stirred magnetically. In accordance with the desired degree of carbonate substitution, an appropriate amount of $\mathrm{NaHCO}_{3}$ or $\mathrm{Na}_{2} \mathrm{CO}_{3}$ (Acros-Organics, 99.5\% or GFS Chemicals, Primary Standard) was dissolved directly in the $250 \mathrm{~mL}$ reactor bath, and the $\mathrm{pH}$ was elevated to $9.0 \pm 0.5$ and maintained with $0.1 \mathrm{M} \mathrm{NaOH}$ (Acros, 97\%). To the bath, $25 \mathrm{~mL}$ of a $0.15 \mathrm{M} \mathrm{Ca}\left(\mathrm{NO}_{3}\right)_{2} \bullet 4 \mathrm{H}_{2} \mathrm{O}$ (Sigma-Aldrich, 99\%) and $25 \mathrm{~mL}$ of a $0.09 \mathrm{M} \mathrm{NaH} \mathrm{PO}_{4}$ (Alrich, $98 \%)$ solution were added at a rate of $1 \mathrm{drop} / 2-4$ seconds. After addition was complete, the mixture was digested at temperature for 2 hours. After the digestion, heating and stirring were discontinued. The mixture was cooled to room temperature and then filtered in a medium porosity glass filter crucible. The product was washed three times with warm water, air dried in a desiccator overnight, and then dried in a 120 ㅇ $\mathrm{C}$ vacuum pistol or an evacuated vacuum desiccator for a minimum of 24 hours. 20 powders were made with $\mathrm{CO}_{3}{ }^{2-} / \mathrm{PO}_{4}{ }^{3-}$ molar ratios ranging from 0.2 to 12 (Table 1 ).

\section{Carbonate Concentration Determination}

\section{CHN analysis}

In order to accurately measure the carbonate concentration of the apatite powders Carbon-HydrogenNitrogen (CHN) analysis was performed by Galbraith Labs, Knoxville, TN. Analysis was performed by combusting the samples and measuring the levels of $\mathrm{CO}_{2}, \mathrm{H}_{2} \mathrm{O}$ and $\mathrm{N}_{2}$ (or $\mathrm{NO}_{\mathrm{x}}$ ) by either an infrared cell or a thermal conductivity detector. Levels were reported as weight percents (wt\%). 


\section{Raman analysis}

Raman analysis was also used to determine the carbonate concentration as well as analyze the atomic order. The Raman microprobe apparatus (HoloLab Series 5000 fiber optically coupled Raman Microscope, Kaiser Optical Systems, Inc) has been previously described. [36]. Spectra were acquired using a $532 \mathrm{~nm}$ laser focused to a $\sim 1 \mu \mathrm{m}$ spot size by an $80 \mathrm{X}$ objective (N.A. $=0.85$ ) at a power of $10 \mathrm{~mW}$ on the sample surface. Scattered light was collected in 32 4-sec acquisitions through the objective lens and transferred to a 2048channel CCD detector. Powders were manually compressed before analysis, and spectra were obtained at six independent locations within each powder.

Spectra for 20 of the powders were analyzed as described previously. [36-39] Briefly, the spectra were background corrected in the region of $700-1200 \Delta \mathrm{cm}^{-}$ ${ }^{1}$ and the peaks were deconvolved into their component bands by applying a mixed Gaussian-Lorentzian peak fitting algorithm using the Grams32 software package (Galactic, Salem, NH). The relative carbonate concentration was determined from the ratio of the areas for the band associated with carbonate substituting for phosphate, i.e. 1070 $\Delta \mathrm{cm}^{-1}$, and the $\mathrm{V}_{1} \mathrm{P}-\mathrm{O}$ stretch band of hydroxylapatite at $960 \Delta \mathrm{cm}^{-1}$ (Fig. 1A). Weight percent of carbonate was determined from a calibration curve developed in our laboratory. In addition, full width at half maximum (FWHM) of the $960 \Delta \mathrm{cm}^{-1}$ peak was used to evaluate the relative atomic order of 12 of the samples. FWHM is inversely proportional to atomic order with a larger FWHM representing a less atomically ordered structure.
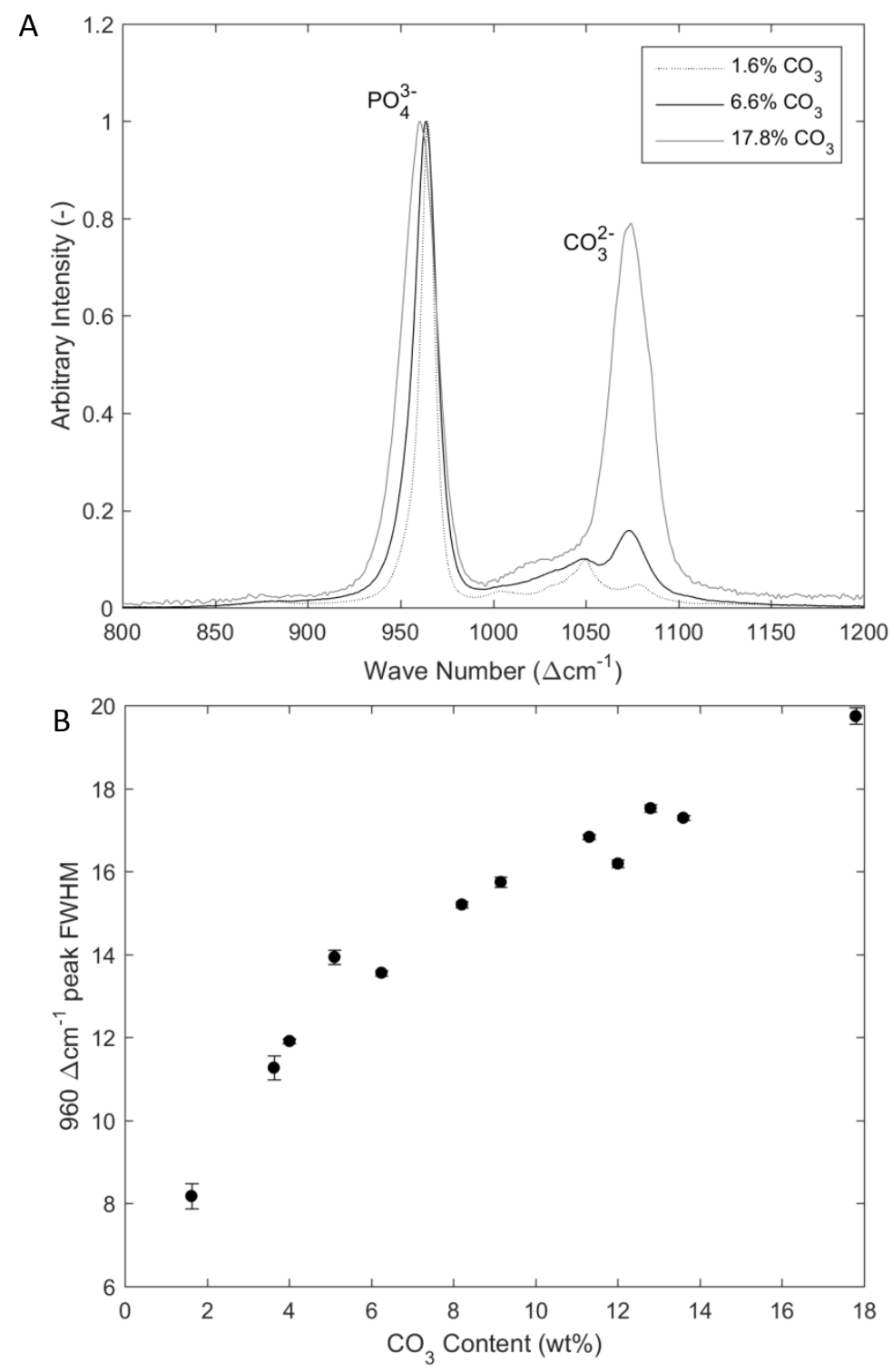

Figure 1: A) Raman Spectra for sample ranging from 1.6-17.8 $w t \%$ carbonate. B) Plot of the width of the $960 \Delta \mathrm{cm}^{-1}$ Raman peak as a function of wt\% carbonate content as determined by $\mathrm{CHN}$ analysis. The peak width is inversely proportional to the atomic order component of crystallinity of the sample; Ramanderived atomic order of the samples decreases with increasing carbonate substitution. 


\section{FTIR analysis}

FTIR analysis was used to determine the carbonate concentration as well as the types of carbonate present in the samples. Transmission Fouriertransform infrared spectroscopy (FITR) analyses were carried out at room temperature on a Thermo Nicolet 5700 spectrometer providing spectral acquisitions in the wavenumber range $400-4000 \mathrm{~cm}^{-1}$. For each acquisition, 128 scans were recorded, with a resolution of $2 \mathrm{~cm}^{-1}$. Of particular interest in this contribution were spectral analyses in the ranges $840-910 \mathrm{~cm}^{-1}$ and $1300-1600$ $\mathrm{cm}^{-1}$, where the vibrational modes $\mathrm{v}_{2}\left(\mathrm{CO}_{3}\right)$ and $\mathrm{v}_{3}\left(\mathrm{CO}_{3}\right)$ of carbonate ions in apatite compounds can be observed, respectively (Fig. 2). Prior to the comparison of spectral features (especially in terms of band integrated intensity), all spectra were baselinecorrected and then normalized, taking as reference (fixed to an absorbance of 1) the maximum absorption between 1033 and $1048 \mathrm{~cm}^{-1}$, depending on the samples, arising in the $\mathrm{v}_{3}\left(\mathrm{PO}_{4}\right)$ domain of phosphate ions.

The evaluation of carbonate concentrations via FTIR was undertaken by following a recently reported methodology based on the peak area ratio between the $\mathrm{v}_{3}\left(\mathrm{CO}_{3}\right)$ and the $\mathrm{v}_{1} \mathrm{v}_{3}\left(\mathrm{PO}_{4}\right)$ contributions [40]. This ratio carbonated apatite compounds, whether of biological or synthetic origins, as validated by direct $\mathrm{CO}_{2}$ coulometry titrations.

A

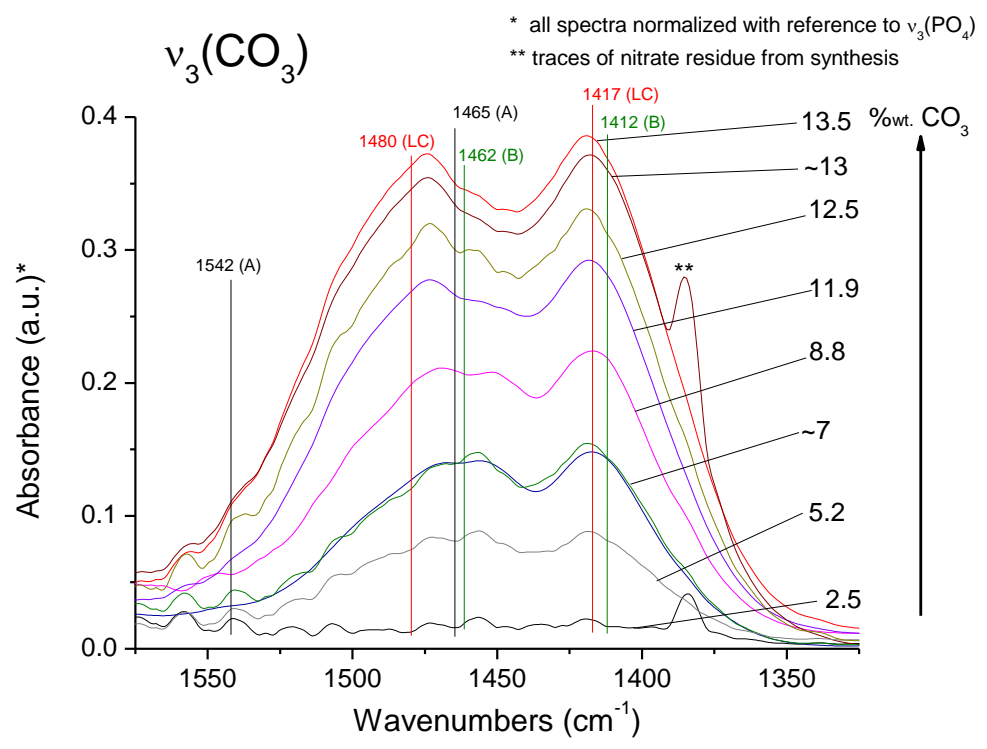

B

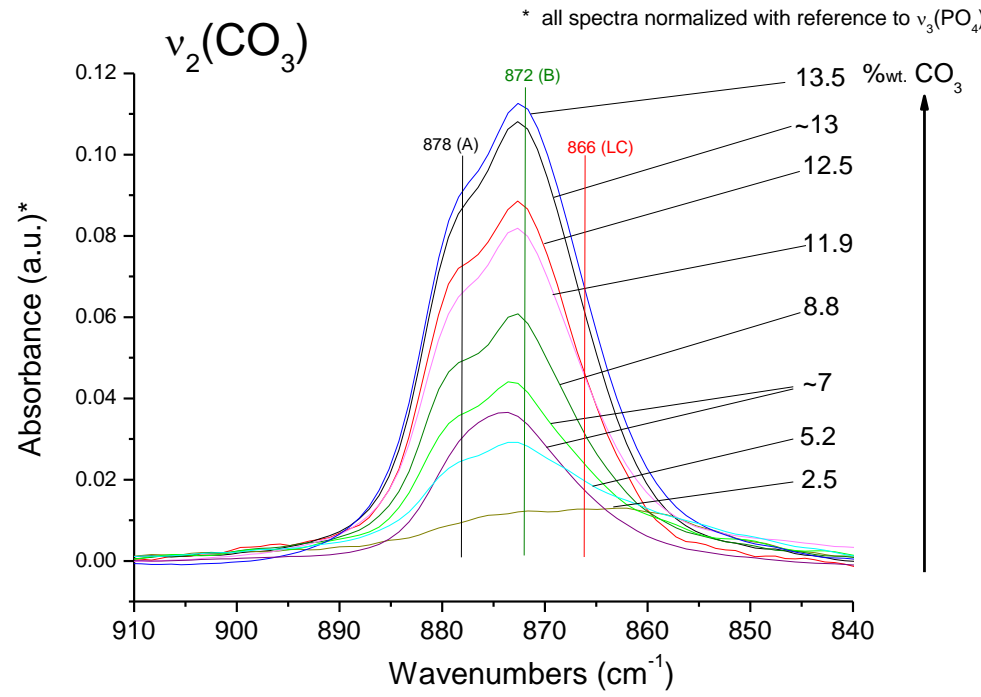

Figure 2: FTIR spectra in the ranges of (A) $1300-1600 \mathrm{~cm}^{-1}$ for the analysis of the carbonate vibration mode $\mathrm{v}_{2}\left(\mathrm{CO}_{3}\right)$, and the range of (B) $840-910 \mathrm{~cm}^{-1}$ for $\mathrm{v}_{3}\left(\mathrm{CO}_{3}\right)$. Peaks at 1462,1412 , and 872 $\Delta \mathrm{cm}^{-1}$ indicate B-type carbonate substitution for phosphate. Their intensity increases with increased carbonate content. Shoulders and small peaks at 1542,1465 , and $878 \Delta \mathrm{cm}^{-1}$ indicate lesser levels of A-type substitution in most samples. In addition all samples exhibit the presence of surface labile carbonate (LC) by peaks at 1480,1417 , and $866 \Delta \mathrm{cm}^{-1}$.

was indeed previously demonstrated to be directly correlated to the carbonate concentrations of 


\section{Solubility determination}

An 80-mg sample of each of 6 carbonated apatite powders was added to $50 \mathrm{ml}$ of phosphate buffer (prepared by dissolving $117.1 \mathrm{~g} \mathrm{NH}_{4} \mathrm{H}_{2} \mathrm{PO}_{4}$ in $1 \mathrm{~L} \mathrm{H}_{2} \mathrm{O}$ ) and equilibrated for 8 days at room temperature. In each case, excess powder still remained in the beaker. Samples were then centrifuged for $10 \mathrm{~min}$ after which the supernatant was removed and filtered through a $22 \mu \mathrm{m}$ syringe filter. The $\mathrm{pH}$ was measured for each solution. The supernatant solutions were further filtered through $0.22 \mu \mathrm{m}$ filters (PES membranes, Environmental Express), diluted, and acidified to $1 \% \mathrm{HNO}_{3}$ before analysis. Concentrations of elements were measured with inductively coupled plasma-mass spectrometry (ICP-MS, Perkin-Elmer). Laboratory blanks $\left(1 \% \mathrm{HNO}_{3}\right)$, calibration standards, and internal standards were included for quality control. Blanks were measured before, during, and after apatite samples. Standards for making calibration curves were prepared in a range of $0.05 \mathrm{mg} / \mathrm{L}$ to $20 \mathrm{mg} / \mathrm{L}$ for major elements (Ca, Mg, Na, and $\mathrm{K}$ ). Internal standards $(20 \mu \mathrm{g} / \mathrm{L} \mathrm{In,} \mathrm{Li}$, and $\mathrm{Bi}$ ) were added online to all samples and standards during ICP-MS analysis. Weighted calibration curves were determined based on external standards and internal standards. The specific detection limit for each element was determined by examination of the blanks and the lowest-concentration calibration standards. Phosphate concentrations were determined by the ascorbic acid method (wavelength at $880 \mathrm{~nm}$ for spectrophotometer)[41].

Assuming a simplified formula for carbonated apatite of $\mathrm{Ca}_{10-x} \mathrm{Na}_{2 \times / 3}\left(\mathrm{PO}_{4}\right)_{6-x}\left(\mathrm{CO}_{3}\right)_{x}(\mathrm{OH})_{2-x / 3}$, and considering $100 \%$ B-type carbonation and the absence of protonated phosphate ions, $x$ was calculated from the analyzed concentrations of $\mathrm{Ca}^{2+}, \mathrm{Na}^{+}, \mathrm{PO}_{4}{ }^{3-}$, and $\mathrm{CO}_{3}{ }^{2-}$ using Visual MINTEQ software. Formulas are listed in Table 1.

\section{$\underline{\text { TEM }}$}

Small quantities of each of the 20 carbonated apatite powders were suspended in methanol and sonicated to minimize aggregation. Twenty microliters of each suspension was deposited on holey carbon TEM grids over filter paper. The grids were allowed to dry before imaging. The powders were imaged with a Hitachi H7500 (Hitachi High Technologies) equipped with a 5-megapixel AMT XR50 camera (Advanced Microscopy Techniques, Woburn, MA). All images were obtained at a beam energy of $80 \mathrm{kV}$.

$\underline{X R D}$

X-ray diffraction measurements were performed on 6 powder samples on a Bruker d8 Advanced X-ray Diffractometer with a $\mathrm{Cu} \mathrm{K} \alpha$ tube source and a LynxEyeXE detector (Bruker, Madison, WI). Scans were performed from $20^{\circ}-60^{\circ}$ with a step size of $0.02^{\circ}$ and an acquisition rate of $0.5 \mathrm{sec} / \mathrm{step}$. To avoid issues with preferential orientation, the sample was rotated at rate of 15 rotations per minute. The system voltage and current were set to $40 \mathrm{kV}$ and $40 \mathrm{~mA}$, respectively. 
Peak fitting was performed on the x-ray diffraction patterns using Diffract.Suite Topas software. Structural refinement was used to fit the (002) and (300) peaks to obtain crystal size and lattice spacing along the c- and a-axes, respectively (Fig. 3). Rietveld analysis was also performed on the entire diffractogram to obtain values of coherent domain size.

Modeling

Molecular Simulations

An interatomic force field was used that has been empirically derived specifically for hydroxylapatite based on a variety of experimental parameters, such as the crystal structure and elastic constants, bond dissociation energies, and vibrational data on the phosphate group. $[42,43]$ In this force field, the nonbonded interactions are modeled by a Buckingham potential, the covalent bond by a Morse potential, and the bond-bending term by a simple harmonic function. This force field shows very good agreement with both density functional theory (DFT) calculations and experiments regarding the crystal structure, the elastic properties, and surface energies. [44-46] This potential has been developed to be compatible with existing carbonate potential and has been used to study the structure of carbonated apatites. [47] In order to reduce the computational cost of the simulations, the electronic polarizability of the oxygen atoms has not been taken into account.

All molecular dynamics simulations were performed using the LAMMPS code. [48] Buckingham and Coulomb interactions were computed with a switch function that ramps the energy and force smoothly to zero between an inner and outer cutoff of $8 \AA$ and $10 \AA$ respectively. The bulk and surface energy models were simulated using periodic boundary conditions and Ewald summation for long-range interactions. The strain was applied by imposing a deformation on the sample. The energies and stresses were recorded after energy minimization.
A
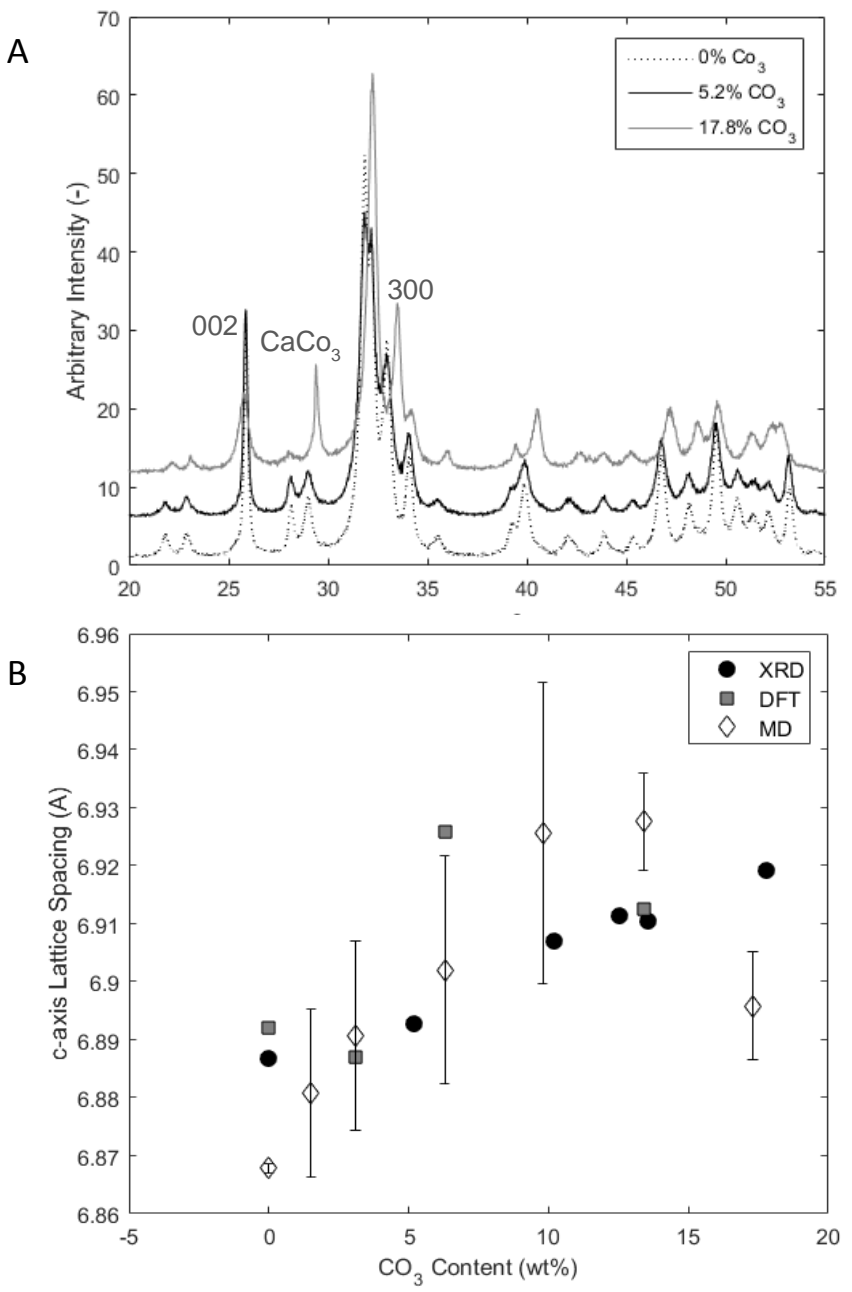

C

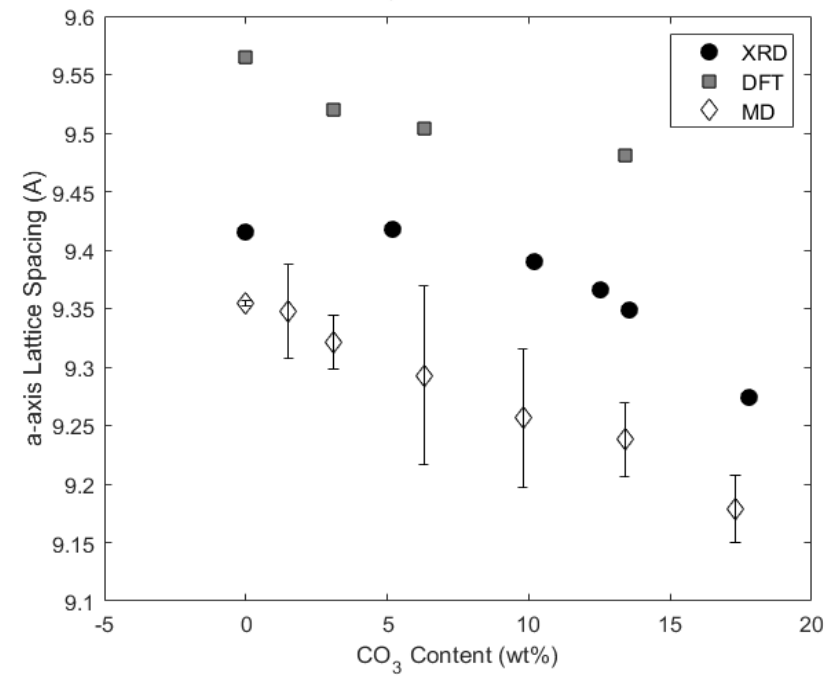

Figure 3: A) XRD pattern for samples containing 0, 5.2, and $17.8 \mathrm{wt} \%$ carbonate. The (002) and (300) peaks shift in opposite directions with increased carbonate content. These shifts represent changes in the lattice spacing. B) Lattice spacing along the $c$-axis as a function of carbonate content measured experimentally from the XRD pattern and theoretically via DFT and MD methods. c-axis lattice spacing increases with the addition of carbonate. C) Lattice spacing along the a-axis as a function of carbonate content measured experimentally from the XRD and theoretically via DFT and MD methods. a-axis lattice spacing decreases with the addition of carbonate. 
Atomistic models of apatite crystals

For computational simplification, an 88-

atom orthorhombic unit cell was used

instead of the classical 44-atom

hexagonal unit cell, to model

stoichiometric hydroxylapatite.

Hydroxylapatite crystallizes in a

hexagonal lattice. However, the

modeling of mechanical properties can

be simplified by mathematically

$0 \%$

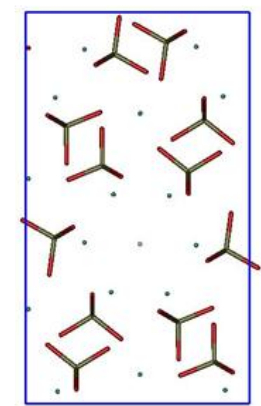

transforming it into an orthorhombic cell

[49](Fig. 4) (Material Studio 4.4,

Accelerys, Inc.). To maintain the

periodicity of the lattice in the

orthorhombic description, it is necessary

to double the unit cell along the $b$ axis.

As a result, the orthorhombic unit cell is twice as large as the hexagonal unit cell and contains 88 atoms. The initial lattice parameters were chosen to match reported experimental measurements with the initial values $a=9.424 \AA, b=$ $16.322 \AA, c=6.879 \AA, \alpha=\beta=\gamma=90^{\circ}$ [50]. The orthorhombic unit cell features characteristics almost identical to those in the hexagonal unit cell and can include substitution. The model samples were created by replication of the unit cell in three dimensions to form a rectangular prism with initial dimensions $2 \mathrm{a} \times \mathrm{b} \times 2 \mathrm{c}$. All the surfaces of the samples have been structured in their charge neutral stoichiometric form [51].

In this study, only B-type carbonate substitution, which is the dominant substitution mechanism in bone mineral and in our synthetic carbonated apatites, was investigated. Also, the protonation of some phosphate ions, leading to $\mathrm{HPO}_{4}{ }^{2-}$ ions instead of $\mathrm{PO}_{4}{ }^{3-}$, was not considered in the calculations: the presence of divalent anions was only accounted for here by the presence of carbonate species. In order to introduce substitutions in the models, phosphate ions were randomly selected in the original structure and replaced with carbonate ions (Visual Molecular Dynamics [52]). To make the model computationally more tractable, charge neutrality was simplified by removing one calcium atom for 
every two carbonate substitutions to compensate for the electron loss occurring during the substitution process [44]. Thus, $\mathrm{OH}$-vacancies were not considered.

The extent of substitution was chosen to span from $0-17 w t \%$, beyond the physiological range of carbonate-substitution measured experimentally in bone apatite. [18, 22, 23] Models were created for $0,1.5,3.1,6.3,9.8,13.4$, and $17.3 \mathrm{wt} \%$ of carbonate substitution. The position and orientation of the carbonate ions were selected randomly to explore the influence of carbonate location on the structure properties. The substitution sites were chosen to be at least $4.5 \AA$ apart. For each amount of substitution modelled, the properties presented here are the average of 5 simulations with different substitution distributions.

\section{Density functional theory calculations}

Density functional theory (DFT) was used to compute the lattice constants and elastic constants, of carbonate-substituted apatite and end-member hydroxylapatite. The QUANTUM ESPRESSO package was used for DFT calculations with the exchange and correlation interaction defined by PBE functional and for the electron-core interaction, ultrasoft pseudopotentials were used. [53] The energy cutoff of 60 Ry is used for plane-wave basis sets and 360 Ry for charge density. For bulk calculations a $2 \times 1 \times 2 k$-point grid has shown convergence of energy (energy difference between two consecutive steps is smaller than $10^{-6}$ Ry), and forces are less than $30 \mathrm{meV} / \AA \AA$ ( $\left.10^{-3} \mathrm{Ry} / \mathrm{Bohr}\right)$. DFT calculations have been performed for $0 \mathrm{wt} \%$, $6 \mathrm{wt} \%$ and $13 \mathrm{wt} \%$ carbonate concentration on a single unit cell to determine the lattice and elastic constants. In the DFT models, the positions of the substitutions have been selected based on previous studies to minimize the total energy of the system.[44]

\section{Elastic constants}

The elastic constants were computed by fitting Hooke's law for both stress-strain (Molecular Static) and energy-strain (DFT) relations for infinitesimal deformation. $[45,54]$ Six different strain modes $\varepsilon_{\alpha \beta}$, $\alpha, \beta \in / x, y, z /$ were applied with each ranging from $-1.0 \%$ to $1.0 \%$ with a step of 0.2 . The ground state energy versus lattice strains were plotted to obtain elastic constants corresponding to each direction $x, y$ and $z$. The following equation was used for the computation of the elastic constants:

$C_{i j k l}=\frac{1}{\Omega} \frac{\partial^{2} E_{t o t a l}}{\partial \varepsilon_{i j} \partial \varepsilon_{k l}}$

where $U=\frac{E_{\text {total }}}{\Omega}$ is the total energy per unit volume in the samples, $\varepsilon_{i j}$ is the strain tensor and $\Omega$ is the unit cell volume of the computational model, and $E_{\text {total }}$ is the ground state unit cell energy. Due to the symmetry of the hexagonal crystals, hydroxylapatite can be considered as a transversely isotropic material and its stiffness matrix can be expressed as: 
$C=\left(\begin{array}{ccccccc}C_{11} & C_{12} & C_{13} & & 0 & 0 & 0 \\ C_{12} & C_{11} & C_{13} & & 0 & 0 & 0 \\ C_{13} & C_{13} & C_{33} & & 0 & 0 & 0 \\ 0 & 0 & 0 & C_{44} & 0 & 0 \\ 0 & 0 & 0 & 0 & C_{44} & 0 \\ 0 & 0 & 0 & 0 & 0 & \frac{C_{11}-C_{12}}{2}\end{array}\right)$

\section{Surface energies}

The surface energy is the excess energy associated with the creation of a free surface for a crystallite with a particular composition. To compute the surface energy, free surfaces were created by adding a $40 \AA$ thick vacuum on each side of the sample in the direction orthogonal to the surface of interest (Fig. 4). The unit cell was duplicated 2 times in the direction orthogonal to the surfaces in order to avoid interactions between the two created surfaces. The dimensions of the sample and vacuum layer were chosen to provide a minimum distance of $10 \AA$ \& between the free surfaces to avoid interaction between the formed interfaces. After relaxation of the structure, the surface energy is given by:

$\gamma=\frac{E_{S}-E_{B}}{A}$

Where $\gamma$ is the surface energy, $E_{S}$ is the energy of the sample with free surface, $E_{B}$ the energy of the equivalent bulk crystal, and $A$ the free surface area. This approach was used to determine the (001) plane surface energy (not considering here the presence of a hydrated layer on the crystallites).

Scaling Laws for Crystallite Size

Scaling laws for crystallite size were generated from the first principles simulation data using the Griffith-Irwin framework and Weibull statistics. The probability of fragmentation during crystal growth dominated by extension in a single direction was taken to follow the Weibull distribution [55]:

$F(\sigma, L, C)=1-\exp \left[-\frac{L}{L_{o}(C)}\left(\frac{\sigma}{\sigma_{o}(C)}\right)\right]^{m(C)}$,

where $F$ is the probability of fragmentation as a function of the substitution-induced lattice stress $(\sigma)$ for an apatite crystallite of length $L$ and carbonate concentration $C$; and $L_{o}(C), \sigma_{o}(C)$, and $m(C)$ are material parameters that depend upon $C$. From data for a range of ceramics, it is reasonable to approximate $m(C)$, the Weibull modulus as a function of carbonate concentration, as invariant with respect to $C$ : $m(C)=m_{\text {o. }}$ [56] In the carbonated apatite system there is not an external applied load, but rather an internal change in lattice spacing that modifies the atomic organization and crystal energetics. This change in lattice spacing can be defined as a lattice strain, which is simply the change in spacing with carbonate concentration divided by the original spacing at 0 wt\% carbonate: $\varepsilon(C)=\left(D-D_{0}\right) / D_{0}$. As for substitutional solid solution strengthening within the Hume-Rothery framework, a lattice strain of $\varepsilon(C)$ along the length of the crystallite results in both elastic and inelastic effects on the lattice, of which we take the elastic part to be proportional to $\varepsilon(C): \sigma=\alpha E(C) \epsilon(C)$, in which $\alpha$ is a constant of proportionality. 
$L_{0}(C)$ is chosen such that it represents the length expected to contain a single critical flaw when $\sigma=\sigma_{0}(C)$. This choice is equivalent to arbitrarily choosing a value $F=1-1 /$ e as the probability of fracture that defines the mean crystallite size at a certain value of $C$. Then,

$\frac{L}{L_{o}(C)}\left(\frac{\sigma}{\sigma_{o}(C)}\right)^{m_{o}}=1$

It was therefore assumed that the distribution of flaw sizes does not vary with $\mathrm{C}$, which follows from the assumption that $m$ is also invariant. The scaling procedure involves identifying the parameters $L_{o}\left(C_{o}\right)$ from the experimental crystallite size data, and applying $E\left(C_{0}\right)$ and $\varepsilon\left(C_{0}\right)$ from the modelling results.

Because the Weibull parameter $m$ can be reasonably approximated as invariant with respect to $C$, the distribution of critical flaws can also be approximated as such. The scaling arises from Griffith-Irwin arguments by building from the work of Freudenthal, who noted that the density $n_{c}(C)$ of critical flaws (size $a>a_{c}(C)$ ) in a specimen arises from the defect density $g(a)$ [57]:

$$
\begin{aligned}
& n_{C}(C)=\int_{a_{C}(C)}^{\infty} g(a) d a \\
& =\int_{a_{C}(C)}^{\infty} \frac{m_{o}}{2 L_{o}\left(C_{o}\right)}\left(\frac{a_{C}\left(C_{o}\right)^{\frac{m_{o}}{2}}}{a^{\frac{m_{o}}{2}+1}}\right) d a \\
& =\frac{1}{L_{o}\left(C_{o}\right)}\left(\frac{a_{C}\left(C_{o}\right)}{a_{C}(C)}\right)^{\frac{m_{o}}{2}}
\end{aligned}
$$

Noting that, at an average fragmentation, $n_{C}(C)=1 /\left(A_{o} L_{o}(C)\right)$,

$$
\begin{aligned}
& \frac{L_{o}(C)}{L_{o}\left(C_{o}\right)}=\left(\frac{a_{C}(C)}{a_{C}\left(C_{o}\right)}\right)^{\frac{m_{o}}{2}} \\
& =\left(\frac{K_{I c}(C) \sigma_{o}\left(C_{o}\right)}{K_{I c}\left(C_{o}\right) \sigma_{o}(C)}\right)^{m_{o}}
\end{aligned}
$$

where $K_{l c}$ is the mode I fracture toughness. This relationship is equivalent to noting from equation (4) and the work of Dobbs et al. [58] that the size of the crystallite will be limited by the following equivalences:

$$
\frac{L_{o}(C)}{L_{o}\left(C_{o}\right)}\left(\frac{\sigma_{o}(C)}{\sigma_{o}\left(C_{o}\right)}\right)^{m}=\left(\frac{K_{I c}(C)}{K_{I C}\left(C_{o}\right)}\right)^{m}
$$

Continuing from equation (10) and noting that $K_{\mathrm{Ic}}^{2}(C) \propto E(C) \gamma(C)$, where $\gamma(C)$ is the surface energy:

$$
\begin{aligned}
& \frac{L_{o}(C)}{L_{o}\left(C_{o}\right)}=\left(\frac{K_{I C}(C)}{K_{I C}\left(C_{o}\right)}\right)^{m_{o}}\left(\frac{\sigma_{o}(C)}{\sigma_{o}\left(C_{o}\right)}\right)^{m} \\
& =\left(\frac{E(C) \gamma(C)}{E\left(C_{o}\right) \gamma\left(C_{o}\right)}\right)^{\frac{m_{o}}{2}}\left(\frac{\alpha E\left(C_{o}\right) \epsilon\left(C_{o}\right)}{\alpha E(C) \epsilon(C)}\right)^{m_{o}}
\end{aligned}
$$


$=\left(\frac{E\left(C_{o}\right)}{E(C)} \frac{\gamma(C)}{\gamma\left(C_{o}\right)}\left(\frac{\epsilon\left(C_{o}\right)}{\epsilon(C)}\right)^{2}\right)^{\frac{m_{o}}{2}}$

All values in equation (14) can be determined from the modeling and XRD results except for $m$, the Weibull modulus.

\section{Results}

Synthesis of Carbonated Apatite Powders with variable Carbonate Concentrations

Twenty samples of carbonated apatite were synthesized via aqueous chemical precipitation methods.[30] Carbonate levels were controlled by changing relative proportions of carbonate- and phosphate-containing chemicals during the precipitation process. Precipitated powders of carbonated apatite were removed from solution and rinsed before analysis.

\begin{tabular}{|c|c|c|c|c|c|c|c|}
\hline \multirow[t]{2}{*}{ Sample } & \multicolumn{3}{|c|}{ Measured $\mathrm{CO}_{3}$ wt\% } & \multirow[t]{2}{*}{$\begin{array}{l}\mathrm{CO}_{3} / \mathrm{PO}_{4} \text { in } \\
\text { soln. }\end{array}$} & \multirow{2}{*}{$\begin{array}{l}\text { Size } \\
\text { (TEM) }\end{array}$} & \multirow{2}{*}{$\begin{array}{l}\text { Size Std. } \\
\text { Dev. } \\
\mathrm{nm}\end{array}$} & \multirow[t]{2}{*}{ Stoichiometric Formula } \\
\hline & $\begin{array}{l}\mathrm{CNH}- \\
\text { Analysis }\end{array}$ & Raman & FTIR & & & & \\
\hline OHAp & 0 & & & 0.0 & 71.0 & 52.1 & $\mathrm{Ca}_{10} \mathrm{Na}_{0}\left(\mathrm{PO}_{4}\right)_{6}(\mathrm{OH})_{2}$ \\
\hline 1 & 1.625 & 2.5 & 1.2 & 0.0 & 133.6 & 101.3 & \\
\hline 2 & 3.63 & 5.17 & & 1.6 & 291.8 & 222.0 & $\mathrm{Ca}_{9.4} \mathrm{Na}_{0.4}\left(\mathrm{PO}_{4}\right)_{5.4}\left(\mathrm{CO}_{3}\right)_{0.6}(\mathrm{OH})_{1.8}$ \\
\hline 3 & 4 & 4.1 & & 0.2 & 171.2 & 92.2 & \\
\hline 4 & 4 & 5.17 & 3.3 & 0.3 & 121.0 & 138.0 & \\
\hline 5 & 5.05 & 5.05 & & 0.9 & 109.3 & 50.5 & \\
\hline 6 & 5.1 & 7.39 & 5.3 & 0.2 & 32.0 & 18.7 & \\
\hline 7 & 6.25 & 6.95 & 5.5 & 0.4 & 40.6 & 17.6 & \\
\hline 8 & 6.35 & 6.35 & & 1.1 & 62.0 & 39.7 & \\
\hline 9 & 6.55 & 6.55 & & 0.5 & 58.2 & 25.4 & \\
\hline 10 & 8.2 & 8.79 & 7.8 & 1.3 & 69.5 & 68.5 & \\
\hline 11 & 9.15 & 10.2 & & 2.5 & 85.2 & 78.0 & $\mathrm{Ca}_{8.6} \mathrm{Na}_{0.9}\left(\mathrm{PO}_{4}\right)_{4.6}\left(\mathrm{CO}_{3}\right)_{1.4}(\mathrm{OH})_{1.5}$ \\
\hline 12 & 11.3 & 12.5 & & 5 & 35.2 & 12.7 & $\mathrm{Ca}_{8.3} \mathrm{Na}_{1.1}\left(\mathrm{PO}_{4}\right)_{4.3}\left(\mathrm{CO}_{3}\right)_{1.7}(\mathrm{OH})_{1.4}$ \\
\hline 13 & 11.6 & 11.6 & & 3.3 & 26.5 & 12.8 & \\
\hline 14 & 12 & 11.92 & 10.9 & 2.9 & 54.4 & 28.5 & \\
\hline 15 & 12.8 & 12.35 & 12.7 & 4.3 & 68.1 & 28.0 & \\
\hline 16 & 13.3 & 13.3 & & 7.0 & 35.5 & 12.5 & \\
\hline 17 & 13.6 & 13.5 & & 4 & 22.1 & 5.7 & $\mathrm{Ca}_{8.0} \mathrm{Na}_{1.3}\left(\mathrm{PO}_{4}\right)_{4}\left(\mathrm{CO}_{3}\right)_{2}(\mathrm{OH})_{1.3}$ \\
\hline 18 & 14 & 14 & & 4.0 & 105.5 & 47.3 & \\
\hline 19 & 15.5 & 15.5 & & 12.0 & 33.7 & 10.4 & \\
\hline 20 & $\begin{array}{r}17.8 \\
(22.4)\end{array}$ & (23.7) & & 3.0 & 36.0 & 28.4 & $\mathrm{Ca}_{7.3} \mathrm{Na}_{1.8}\left(\mathrm{PO}_{4}\right)_{3.3}\left(\mathrm{CO}_{3}\right)_{2.7}(\mathrm{OH})_{1.1}$ \\
\hline
\end{tabular}

Table 1: Values characterizing the composition of the apatite samples. Carbonate values in each sample were determined by $\mathrm{CHN}$-analysis, Raman, and in some cases FTIR. The degree of carbonate substitution in the precipitated apatites was controlled by the $\mathrm{CO}_{3} / \mathrm{PO}_{4}$ molar ratio in the precipitation solution. The crystallite dimension of the major axis was determined via visual inspection in the TEM. Stoichiometric formulas were calculated according to [59] based on the compositions acquired by ICP-MS and CHN-analysis. 
Carbonate concentrations in the apatites were measured using Carbon-Hydrogen-Nitrogen (CHN) combustion analysis, Raman spectroscopy, and Fourier Transform Infrared (FTIR) spectroscopy. CHN combustion analysis indicated that the carbonated apatite powders contained between 1.6 and 22.4 wt\% carbonate, Table 1. Raman measurements showed similar values in carbonate concentrations. Differences between the Raman and the $\mathrm{CHN}$ analyses were more pronounced in samples with low carbonate levels.

X-ray diffraction analysis of sample 20, which appeared to contain $22.4 \mathrm{wt} \%$ carbonate, indicated the presence of calcite in the powder sample. Using the carbonate concentrations determined from the $\mathrm{CHN}$ analysis and the simplified formula for carbonated apatite as well as the level of calcite determined from Rietveld analysis of the XRD pattern, it was calculated that the carbonated apatite lattice contained 17.8 wt\% carbonate.

\section{Types of Carbonate Substitutions in the Carbonated Apatite Powders}

FTIR analyses were carried out on 7 of the carbonated apatite samples, with a focus on examining vibrational contributions of carbonate. Two spectral domains were targeted: the range of $840-910 \mathrm{~cm}^{-1}$ for the analysis of the carbonate vibration mode $\mathrm{v}_{2}\left(\mathrm{CO}_{3}\right)$, and the range of $1300-1600 \mathrm{~cm}^{-1}$ for $\mathrm{v}_{3}\left(\mathrm{CO}_{3}\right)$.

The evolution of the $\mathrm{v}_{3}\left(\mathrm{CO}_{3}\right)$ domain for the different samples analyzed showed a general trend of increasing area under the carbonate peaks in this interval, with increasing overall carbonate concentration in apatite (Figure 1A). In carbonated apatite systems, this spectral region is difficult to decompose, as each type of carbonate species (A-type, B-type, or labile surface carbonates denoted LC) roughly gives rise to two main contributions that are overlapping [60]. The general FTIR profiles in this region, however, suggest that more than one type/site of carbonate ion was present in all samples, although in variable amounts. In particular, B-type carbonate appeared to be predominant ; the proportion of A-type carbonate was significantly lower than that of B-type; LC-type (labile non-apatitic surface) carbonate occurred in much lower but non-negligible concentration.

The analysis of the $\mathrm{v}_{2}\left(\mathrm{CO}_{3}\right)$ band (Fig. $2 \mathrm{~B}$ ), with the detection of several shoulders, confirmed the existence of several types of carbonate environments in these samples, as was concluded from the observation of the $\mathrm{v}_{3}\left(\mathrm{CO}_{3}\right)$ domain. However, examination of the $\mathrm{v}_{2}\left(\mathrm{CO}_{3}\right)$ contribution in apatite samples was also complicated by the superimposition of the $\mathrm{P}-\mathrm{OH}$ vibration band of $\mathrm{HPO}_{4}{ }^{2-}$ ions, around 870-875 $\mathrm{cm}^{-1}$, as a broad halo at the bottom of the band. B-type carbonate, and to a lesser extent A-type, were clearly identifiable in the spectra, with $\mathrm{v}_{2}\left(\mathrm{CO}_{3}\right)$ bands around 872 and $878 \mathrm{~cm}^{-1}$, respectively. Also, the band relevant to labile surface carbonate species can give rise to a large contribution; its position is difficult to assess exactly but is usually considered close to the value (around $866 \mathrm{~cm}^{-1}$ ) noted for amorphous carbonate-containing calcium phosphate.[60] As a general trend, the overall area under the peaks in this spectral region increased with the total carbonate concentration of the apatite samples. The reported carbonate values in Table 1 for FTIR are a sum of all of the measured carbonate species.

\section{Determination of Crystallite Size}


The size of the crystallites within the carbonated apatite powders was measured manually from transmission electron microscopy (TEM) images of the dispersed powders. In all cases, the crystallites that composed the apatite powders appeared to be flat plates (Fig. 5). Large crystallites looked blade-like, with clearly defined edges and faceting; however, as the crystals became more carbonated and smaller, the crystallite shape became less well defined and facets were harder to identify. The long axis of the plates decreased with increasing carbonate substitution, from $291.8 \pm 222 \mathrm{~nm}$ to $22.1 \pm 5.7 \mathrm{~nm}$ for an increase in carbonate concentration of $10 \mathrm{wt} \%$ (Table 1). The variability in the crystallites' long dimension also decreased with increasing carbonate substitution.

\section{Strain and Atomic order}

XRD was performed on 6 representative samples to obtain information about how lattice parameters of the carbonated apatite crystals were modified with increased carbonate content. XRD patterns indicated that all the samples were solely carbonated apatite, except for the sample containing $22.4 \mathrm{wt} \%$ total carbonate, which also exhibited small calcite peaks in XRD patterns and Raman spectra. As explained above, this calcite was accounted for and a true latticeincorporated carbonate concentration of $17.8 \mathrm{wt} \%$ was calculated for this sample. D-spacing values calculated from the peak center for the (002) and (300) peaks

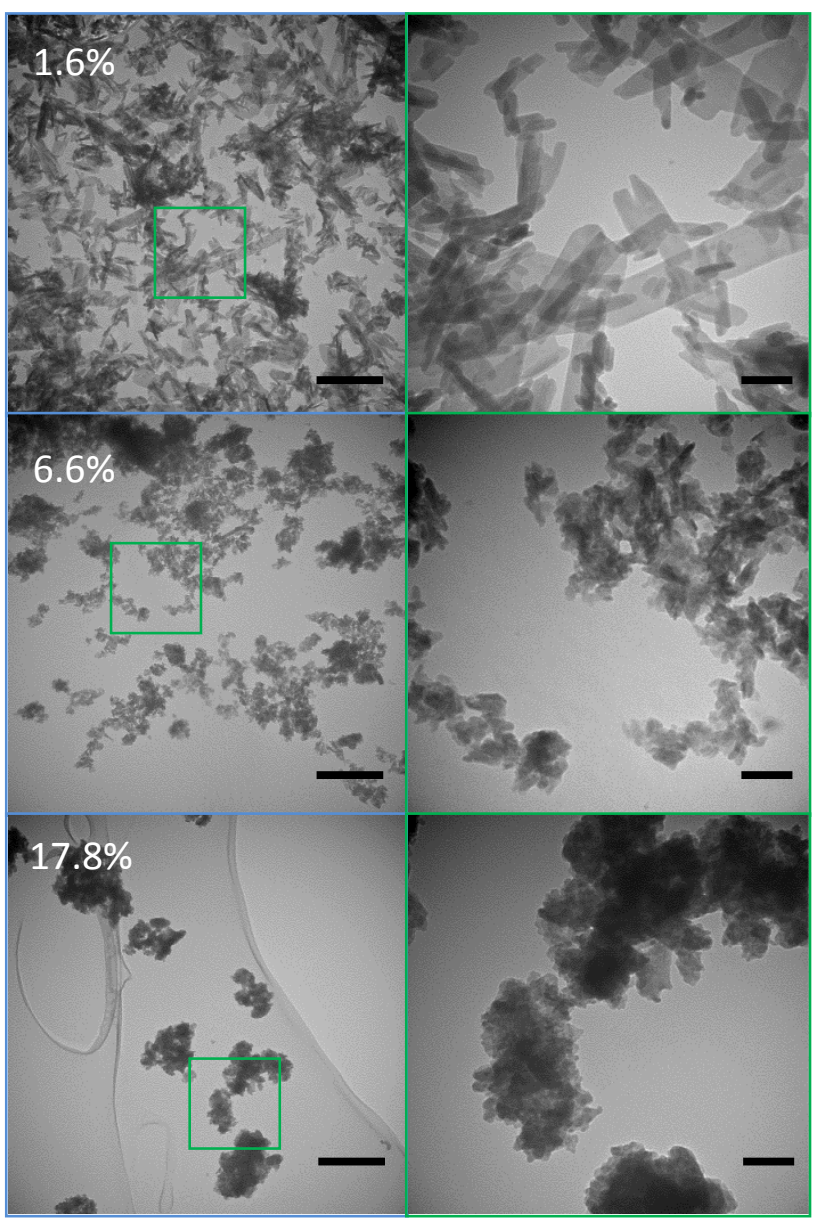

Figure 5: TEM images of three carbonated apatites containing $1.6 \%, 6.6 \%$, and $17.8 \%$ carbonate by weight. Right hand images are $4 \mathrm{X}$ enlargements of indicated areas on the left. . As carbonate content increases, the particles tend be smaller and have a greater propensity for aggregation. Scale bars are $500 \mathrm{~nm}$ for the left column, $100 \mathrm{~nm}$ for the right column. indicated a $0.5 \%$ increase in lattice spacing along the c-axis (6.887 to $6.919 \AA$ ) and a decrease of $1.5 \%$ along the a-axis ( 9.417 to $9.274 \AA$ ) as the carbonate value increased from 1 to 17.8 wt\% (Fig. 3). With that same increase in carbonate, the coherent domain size, defined as the distance between grain boundaries or significant defects within the crystallites, along the c-axis decreased from 49.8 to $16.3 \mathrm{~nm}$, representing a $67 \%$ decrease in domain size. The aspect ratio c:a of the coherent domains also decreased from 3.4 to 0.63 with the same change in carbonate.

The FWHM of the $960 \Delta \mathrm{cm}^{-1}$ Raman band, which is inversely proportional to the degree of atomic order or atomic order of the sample, increased with increasing carbonate concentration. The increase was not linear with respect to wt\% $\mathrm{CO}_{3}$, but rather exhibited a decrease in slope with increasing carbonate level (Fig. 1). 
Modeling of Carbonated Apatite

Molecular statics and molecular dynamics (MD) methods as well as density functional theory (DFT) were used to predict the lattice, elastic and surface energy values of hydroxylapatite and carbonatesubstituted apatite. These methods were applied to a geometrically simplified orthorhombic model of apatite, which actually is crystallographically hexagonal (Fig. 4). Since DFT calculations are computationally expensive, DFT was used to validate the MD predictions of elastic and lattice constants for the $0 \mathrm{wt} \%, 6 \mathrm{wt} \%$ and $13 \mathrm{wt} \%$ cases. Below, comparisons of both simulation and experimental results are discussed.

\section{Modeled lattice constants and strain}

The evolution of the modeled lattice parameters, as a function of carbonate concentration, is presented in Fig. 3B-C. Both DFT and MD results were in good agreement with experimental analyses. Introducing carbonate ions into hydroxylapatite led to a significant decrease in both $a$ and $b$ lattice constants, indicating a decrease in $a$ in the true hexagonal unit cell. The transverse lattice parameters $a$ and $b$ decreased linearly with the amount of substitution, and the lattice strain rose to $1.5 \%$ for $13 \mathrm{wt} \%$ substitution according to the simulation results (Fig. 3C). In contrast, the lattice parameter along the crystal $c$-axis increased linearly with carbonate substitution. The lattice strain in the c-direction was more moderate than in the $a$ - and b-directions, reaching $0.5 \%$ for $13 \mathrm{wt} \%$ substitution (Fig. 3B). The modeling results showed that the lattice strain along the $c$-axis was more sensitive than along the $a$-axis to the location of the substitution sites in the crystal structure.

\section{Elastic moduli}

Simulations indicated that carbonate substitution changes the mechanical properties of bone at the nanoscale, i.e., at the crystallite level. The elastic constants of end-member (non-carbonated) hydroxylapatite computed using both DFT and MD (Table 2 and in Fig. 6) were in close agreement with previous simulations $[45,50]$ and experiments [61]. The simulations predicted a decrease in moduli with increasing carbonate substitution, with significant differences for the constants $C_{33}, C_{13}$, and $C_{44}$. These values decreased almost linearly as a function of carbonate concentration. In both the MD and DFT calculations, the transversely isotropic behavior of the crystal was well conserved, as would be expected in the true hexagonal apatite crystal (Table 2).

\section{Surface energy considerations}

The computed surface energy value for the (001) surface using MD is given in Table 2. Introducing $\mathrm{CO}_{3}{ }^{2-}$ into the crystal lattice led to a decrease in the surface energy for the (001) surface. For example, the computed surface energy value for the (001) surface decreased from $\gamma=1.04 \mathrm{~J} / \mathrm{m}^{2}$ for pure hydroxylapatite to $\gamma=0.53 \mathrm{~J} / \mathrm{m}^{2}$ for a sample containing $13 \mathrm{wt} \%$ of substituted carbonate (Table 2). This surface energy evaluation corresponds to an idealized estimate, not considering the presence of a nonapatitic layer on the surface of the nanocrystals. Although this estimate is not fully representative of the nanocrystals' behavior, it provides insights into how the presence of carbonate ions in the crystalline core may influence the surface energies of a crystallite. 


\begin{tabular}{|c|c|c|c|c|c|c|c|}
\hline & \multicolumn{3}{|c|}{$0 \mathrm{wt} \% \mathrm{CO}_{3}$} & \multicolumn{2}{|c|}{$6 \mathrm{wt} \% \mathrm{CO}_{3}$} & \multicolumn{2}{|c|}{$13.4 \mathrm{wt} \% \mathrm{CO}_{3}$} \\
\hline & MD & DFT & Experimental & MD & DFT & MD & DFT \\
\hline & \multicolumn{7}{|c|}{ Elastic Constants (GPa) } \\
\hline C11 & $137.4 \pm 0.3$ & 118.58 & 137 & $126.6 \pm 1.5$ & 117.63 & $114.0 \pm 2.5$ & 118.21 \\
\hline $\mathrm{C22}$ & $138.2 \pm 0.9$ & - & - & $124.5 \pm 2.6$ & - & $117.0 \pm 1.5$ & - \\
\hline C33 & $185.4 \pm 0.3$ & 166.38 & 172 & $140.0 \pm 3.4$ & 148.18 & $106.1 \pm 1.7$ & 128.02 \\
\hline C12 & $49.4 \pm 0.3$ & 32.27 & 43 & $52.2 \pm 1.2$ & 49.28 & $48.0 \pm 1.7$ & 29.95 \\
\hline C13 & $70.5 \pm 0.1$ & 65.73 & 55 & $53.6 \pm 1.7$ & 47.39 & $45.0 \pm 1.1$ & 45.35 \\
\hline $\mathrm{C} 23$ & $70.7 \pm 0.3$ & - & - & $52.8 \pm 2.2$ & - & $43.6 \pm 1.0$ & - \\
\hline C44 & $52.1 \pm 0.1$ & 40.4 & - & $37.1 \pm 1.9$ & 28.49 & $30.6 \pm 0.9$ & 24.26 \\
\hline C55 & $51.4 \pm 0.1$ & - & - & $37.5 \pm 1.8$ & - & $30.0 \pm 0.9$ & - \\
\hline \multirow[t]{2}{*}{ C66 } & $44.3 \pm 0.1$ & - & - & $35.4 \pm 1.4$ & - & $33.0 \pm 0.7$ & - \\
\hline & \multicolumn{7}{|c|}{ Moduli (GPa) } \\
\hline B & $91.7 \pm 0.2$ & 77.9 & 89 & $78.5 \pm 1.4$ & 74.3 & $67.5 \pm 2.6$ & 67 \\
\hline \multirow[t]{2}{*}{$\mathbf{E}$} & $120.9 \pm 0.1$ & 103.2 & 114 & $96.8 \pm 2.1$ & 87.7 & $82.8 \pm 3.8$ & 86.2 \\
\hline & \multicolumn{7}{|c|}{ Lattice Parameters ( $(\AA)$} \\
\hline $\mathbf{a}$ & $9.36 \pm 0.00$ & 9.56 & 9.42 & $9.29 \pm 0.08$ & 9.5 & $9.24 \pm 0.11$ & 9.48 \\
\hline b & $16.19 \pm 0.00$ & 16.56 & 16.31 & $\begin{array}{c}16.09 \pm 0.0 \\
1 \\
\end{array}$ & 16.43 & $\begin{array}{c}15.92 \pm 0.1 \\
1 \\
\end{array}$ & 16.33 \\
\hline \multirow[t]{2}{*}{ c } & $6.87 \pm 0.00$ & 6.89 & 6.88 & $6.9 \pm 0.04$ & 6.93 & $6.93 \pm 0.11$ & 6.91 \\
\hline & \multicolumn{7}{|c|}{ Surface Energy $\left(\mathrm{J} / \mathrm{m}^{2}\right)$} \\
\hline$\gamma_{001}$ & $1.04 \pm 0.00$ & - & - & $0.75 \pm 0.04$ & - & $0.54 \pm 0.03$ & - \\
\hline
\end{tabular}

Table 2: Elastic moduli and lattice parameters for pure hydroxylapatite and for 6 and $13.4 \mathrm{wt} \%$ carbonated hydroxylapatite computed using both MD and DFT. The elastic constants $\left(C_{i j}\right)$, the bulk modulus (B), and the elastic modulus (E) are expressed in GPa; the lattice parameters $(a, b, c)$ are in $\AA$, and the surface energies $(\gamma)$ are in $\mathrm{J} / \mathrm{m}^{2}$. Experimental data from [50,61, 62].

\section{Discussion}

The mineral in bone exhibits a nanometer-scale size and plate-like morphology. The nanometer size plays an essential role in bone mechanics allowing the mineral crystallites to be flaw insensitive, thereby increasing bone strength[1]. In addition, the high surface area of the nanocrystals allows for effective dissolution to regulate body $\mathrm{pH} .[2,3]$ Although the importance of the mineral nano-morphology has been established, the mechanisms describing nano-crystal formation, size-control, morphology, and mechanics remain unclear despite extensive study. [22, 25, 26, 30, 63, 64] Here, wide-ranging carbonate concentrations were examined experimentally to establish relationships between carbonate concentration and crystallite size, crystallite shape, and lattice spacing. In addition, MD and DFT modeling approaches successfully interpreted the experimental results. The comprehensive approach of combining experiment with modelling allowed us to define the relationships between carbonate substitution and bioapatite crystal properties in the absence of protein control. Understanding the precipitation of mineral nanocrystals in an in vitro system will help to elucidate physicochemically 
controlled mineralization mechanisms in bone tissues and provide unique information for tailoring mineral properties in tissue engineering systems.

Successful creation of nano-crystalline bone-mineral analogues was accomplished by aqueous precipitation methods at well below $100{ }^{\circ} \mathrm{C}$. CNH-combustion analysis, Raman spectroscopy, and FTIR spectroscopy showed that the suite of apatite samples under analysis contained carbonate levels from 1.6 to 17.8 wt\%, which includes and extends beyond the physiological values of $2-8 \mathrm{wt} \%$ $\mathrm{CO}_{3}{ }^{2-}$ in mammalian bone mineral. $[18,22,23]$ Both biological and synthetic precipitation techniques result in some amount of carbonate deposition on the surface of the crystallites, i.e., not integrated into the lattice structure of the nanocrystals, known as labile carbonate.[65] Within the lattice, $\mathrm{CO}_{3}{ }^{2-}$ can substitute in place of $\mathrm{OH}^{-}$(A-type substitution), $\mathrm{PO}_{4}{ }^{3-}$ (B-type substitution), or both.[21] FTIR analysis of the samples indicated that the carbonate was indeed in the lattice and predominantly incorporated via B-type substitution (with labile species in a non-negligible amount), as shown in Fig. 2. In all tested samples, there were also peak shoulders indicative of lesser amounts of Atype substitution.

Incorporation of the carbonate into the crystal lattice resulted in specific modifications of the apatite lattice structure. When carbonate substitutes for hydroxyl, the a-axis lattice spacing increases. [66] Conversely, B-type substitution for $\mathrm{PO}_{4}{ }^{3-}$ causes the a-axis spacing to decrease and the c-axis spacing to increase. [18, 67-69] Lattice spacing values measured via XRD for the carbonated apatite powders showed that, for all of the apatites, the c-axis spacing increased while the a-axis spacing decreased with increasing carbonate concentrations (Fig. 3), indicative of predominant B-type substitution, the substitution type most commonly seen in bone.[24] Analysis of the composition and
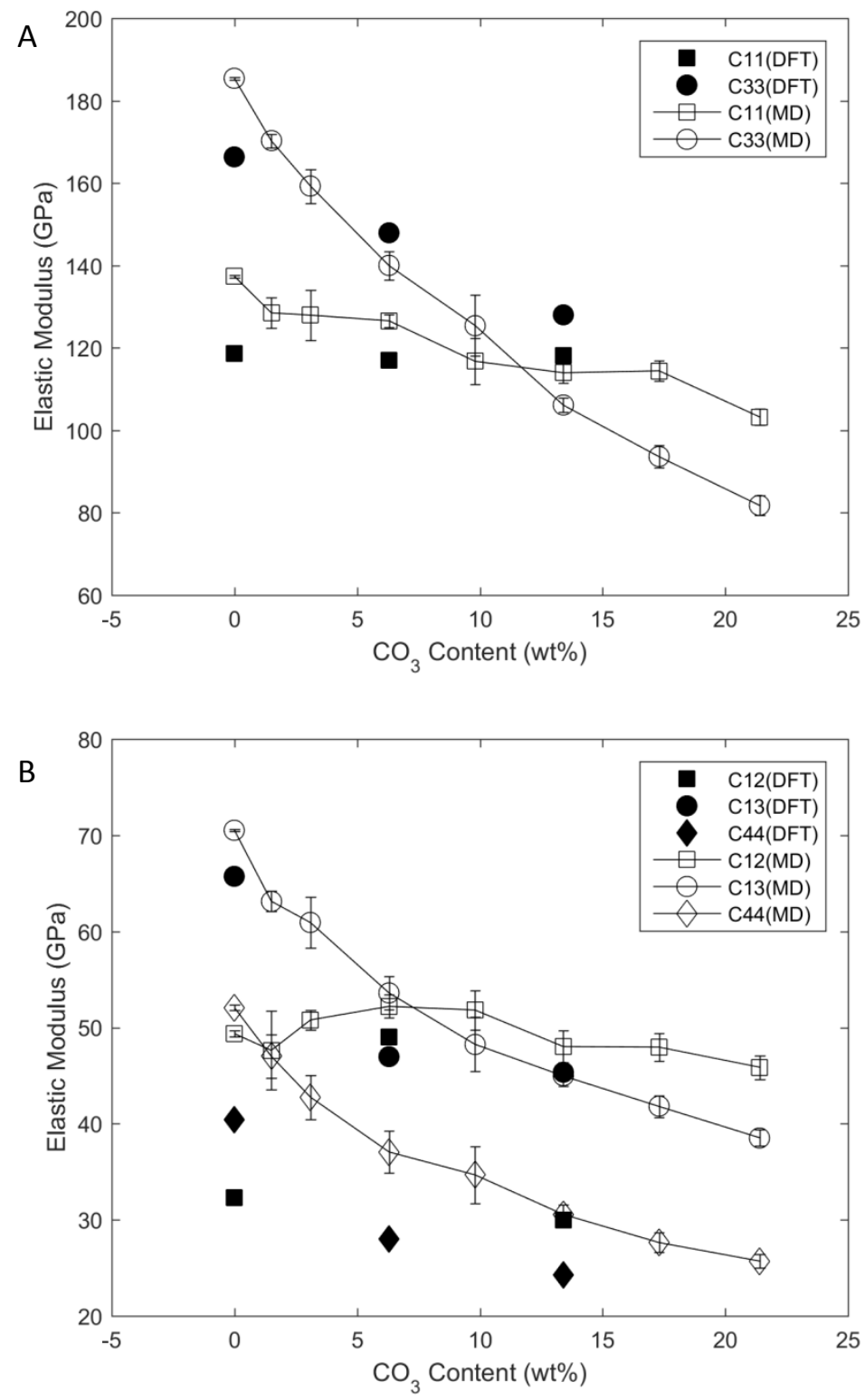

Figure 6: Elastic constants computed with both DFT and Molecular Statics for A) C11 and C33 and B) C12, C13, and C44. The results computed using the two methods show good agreement. Except for C12, all elastic modulus constants decrease significantly with increasing carbonate content in the apatite structure. 
lattice structure of the apatite crystals confirms that the aqueous precipitation technique presented here created some carbonated calcium apatites similar to those found in bone.

Examination of the TEM images indicated that the apatites exhibited decreased crystallite size with an increase in carbonate (Fig. 5). A carbonate-related decrease in crystallite size has been reported previously in the literature. $[8,25,27-29,70]$ At carbonate concentrations below approximately 10 wt\% the maximum crystallite dimension decreased rapidly from values nearing $1 \mu \mathrm{m}$ to tens of nanometers. Above $10 \mathrm{wt} \% \mathrm{CO}_{3}{ }^{-}$the crystallite size plateaued at around $30 \mathrm{~nm}$ (Table 1 and Fig. 7). Although there is no distinct shift in lattice spacing at this composition, a drastic change in the $\mathrm{OH}^{-}$resonance upon approach to $8 \mathrm{wt} \%$ carbonate substitution has been previously observed via NMR.[29] Coherent domain size, the average distance between grain boundaries (or large defects in a crystalline structure), was measured via examination of the width of the XRD peaks and application of Scherrer's equation.[71] Coherent domain size was smaller than the TEM -visualized crystallite size. This apparent inconsistency indicates that the visualized crystallites were polycrystalline.[72] The aspect ratio of both the crystallites and the coherent domains within them also decreased according to both the TEM images and XRD patterns, as seen previously [70]. This suggests that the relative growth rates along the dominant axes were in part controlled by the addition of carbonate. Carbonate concentration seems to be a major controller of crystallite size, maintaining the bone-like mineral in a nanometer size range that most benefits the bone mechanics and physiology.

The morphology of the apatites was also distinctly affected by carbonate concentration (Fig. 5). The shape of biological and biomimetic apatites has been described as plate-like [7-9], needle-like [9, 26, 27], elongated drop-like [26], rod-like [8, 25], and spheroidal [8,27]. Variations in the size and shape of crystallites are recognized to be a function of their composition and formation temperature. [8, 9, 25-27, 63] The powders in this study exhibited plate-like morphologies, in which two dimensions appeared much larger than the third, at all carbonate levels. At low levels of carbonate, the crystallites were larger and blade-like, with visibly straight edges. As carbonate levels increased, the edges became less linear and more uneven. It has been suggested that the loss of obvious faceting on the crystallites may be caused by a decrease in atomic order associated with carbonate incorporation.[8] This proposal is supported by our experimental results showing a decrease in both faceting and atomic order (Fig. 1 and 5 ) with an increase in carbonate concentration. In the range of physiological carbonate concentrations for mammalian bone, $[18,22,23]$ the crystallite length $(\sim 50-100 \mathrm{~nm})$ and plate like morphology are similar to the mineral sizes and shapes generally seen in bone [72].

Although the mechanisms for mineralization of the collagen matrix in bone are poorly understood, both collagenous and non-collagenous proteins have been intimated as responsible for the plate-like nano-scale morphology of the apatite crystallites.[10-12, 14] Collagen molecules self-assemble into well-organized fibrils that exhibit periodic gap and overlap zones every $67 \mathrm{~nm}$. [73, 74] It has been suggested that collagen residues or acidic non-collagenous proteins promote mineralization in the gap zones by either physically or chemically constraining crystal growth into nanometer scale plates. [10, 7578] However, our results indicate that there is no need for collagen templating or interference from 
other organic moieties to produce crystallites that exhibit physiological morphologies and nanometer sizes; instead, controlling carbonate concentrations is sufficient to precipitate such crystallites.

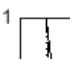

Normalized Crystallite Length

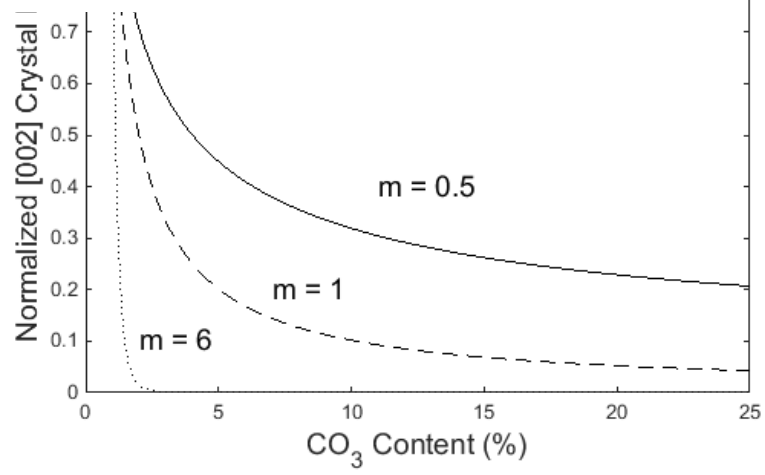

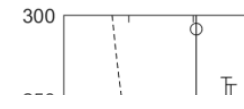

Crystallite Length $(\mathrm{nm})$

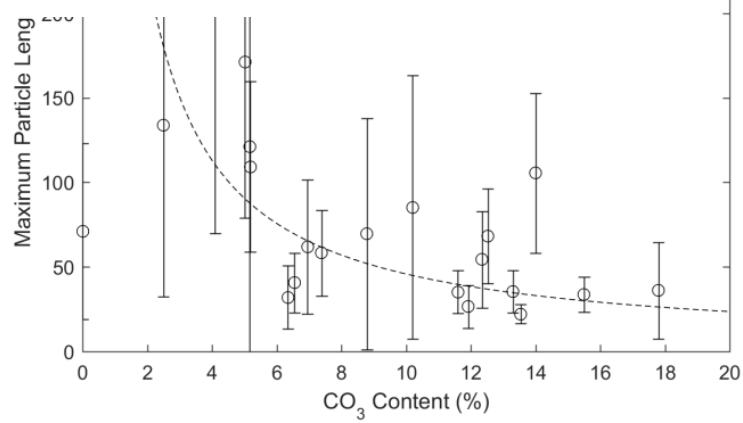

Figure 7: A) Normalized crystallite length vs. carbonate content as calculated from the modified Weibull analysis. Crystallite length exhibits a rapid decrease at low carbonate levels, which plateaus at higher carbonate levels, where the slope and endpoint of the drop are controlled by the Weibull modulus (m). B) Assuming a starting crystallite length at a $\mathrm{CO}_{3}$ concentration of $0 \mathrm{wt} \%$ of $400 \mathrm{~nm}$, the calculated variation in crystallite sizes as a function of carbonate content matches well with the experimental data when $\mathrm{m}=1$.

Comparison of the experimental XRD values with the DFT and MD models demonstrated that the models, which assumed 100\% B-type substitution, were successful in predicting changes in lattice spacing with increased carbonate concentration (Fig 3B-C). The theoretically derived values, especially in the MD simulations, were overestimates of the experimentally measured changes in lattice spacing. This discrepancy may be a result of mixed A- and B-type substitutions in the powders or the release of lattice strain by additional substitutions, such as the incorporation of $\mathrm{Na}$ as a substitute for $\mathrm{Ca}$, which was not accounted for in the models presented here. ICP-MS analyses indicated that there was significant sodium substitution in the structure, which increased with carbonate incorporation, as seen in bone mineral [18-20]. Despite the models' limitations, their success in predicting the lattice parameters of the carbonated apatites makes them credible for further investigation of the crystal properties.

The models were also used to calculate the mechanical properties and theoretical surface energies of the crystals, which are difficult to obtain experimentally. The model results showed that the elastic modulus of the crystals, i.e., their resistance to elastic deformation, decreased with increasing carbonate substitution. These results are in agreement with previous work that has shown that biological bone apatites, which contain carbonate, have a lower modulus compared to carbonate-poor geological apatites $[79,80]$. If bone is considered to be a composite of mineral and collagen, changes to the mineral stiffness and fracture strength due to composition and size effects, as seen here, will have significant consequences for the overall bone mechanics. 
The idealized estimated surface energy of the crystals (especially on the (001) face), not considering the presence of a non-apatitic surface layer on the nanocrystals, also decreased significantly as carbonate incorporation increased. A decrease in surface energy will promote the formation of nanocrystals with high surface areas and low volumes. The trends in lattice strain, modulus, and surface/interfacial energy all indicate that the substitution of carbonate into the apatite structure results in important modifications to the crystal energetics.

Beyond simply correlating the changes in crystal energetics and size, a model was developed to elucidate the mechanistic relationship between these two factors. Estimation of crystallite size from first-principles analysis is a well-known challenge due to the number of atoms that must be considered [81]. A scaling law was developed using the Griffith-Irwin framework and Weibull statistics [82] to relate crystal energetics, including surface energy and the elastic parts of the lattice strain, to the experimentally measured crystallite size. As described in the methods section, the Weibull-type scaling law relating the probability $F$ that a growing crystal with carbonate concentration $C$ will fragment before reaching length $L$ or elastic stress $\sigma$ :

$F(\sigma, L, C)=1-\exp \left[-\frac{L}{L_{o}(C)}\left(\frac{\sigma}{\sigma_{o}(C)}\right)\right]^{m}$

where $L_{o}(C)$ and $\sigma_{o}(C)$ are normalization parameters, and $m$ is the Weibull modulus, a material parameter that is related to the energetics of surface formation and the distribution of flaws in a material; for a nano-ceramic, a Weibull modulus on the order of 1 is expected. As appropriate for brittle materials that fracture at critical defects, this scaling law predicts an increased probability of failure with increasing crystallite volume, which is associated with an increased probability that the crystallite houses a critical defect. The statistical distribution of defect sizes was held invariant with respect to C; therefore, as described in the methods section, $m$ was also held invariant. This enabled us to test the hypothesis that the change in the crystal energetics due to carbonate substitution controls the crystallite size.

Adapting the Weibull relationship for elastic strain of the crystal lattice due to atomic substitution and applying Griffith-Irwin energetic arguments, the scaling relationship between carbonate content and crystallite size as related to crystal energetics is:

$\frac{L_{o}(C)}{L_{o}\left(C_{o}\right)}=\left(\frac{E\left(C_{o}\right)}{E(C)} \frac{\gamma(C)}{\gamma\left(C_{o}\right)}\left(\frac{\epsilon\left(C_{o}\right)}{\epsilon(C)}\right)^{2}\right)^{\frac{m_{o}}{2}}$

where $E$ is the Young's modulus, $\gamma$ is the idealized surface energy on the growing crystal face, and $\varepsilon$ is the lattice strain. All values on the right side of this equation can be determined from the modelling and XRD results except for $m$, the Weibull modulus. For all values of $m$, crystallite length decreased nonlinearly with carbonate concentration, with a rapid drop off at small carbonate concentrations followed by a plateau (Figure 7A). The smaller the $m$ value the steeper the drop in size towards an asymptote. As expected for a ceramic of this character, $m \approx 1$ provided a good fit to the experimentally- 
determined trends for crystallite size vs. carbonate concentration (Figure 7B); supporting our hypothesis that carbonate content controls the nanometer-scale crystallite size.

A necessary consideration was the possible effect of differences in the saturation state of the solutions from which apatites with increasing carbonate concentration were precipitated. The effect of saturation on the differences in crystallite size was investigated by measuring the solubility of individual samples. The reasoning was that differences in solubility at a fixed temperature could lead to variations in the degree of supersaturation given the constancy of calcium and phosphate in the synthesis solutions. Differences in the degree of supersaturation could in turn cause changes in nucleation rate from sample to sample. Solubility products, $K_{s p}$, were measured from the ICP-MS results. $K_{s p}$ values increased from $6 \times 10^{-115}$ to $5 \times 10^{-103}$ for apatite containing 3.6 to $17.8 \mathrm{wt} \%$ carbonate, respectively (Fig S1). Although this is a large increase in solubility, it is unclear what effects this difference would have on the crystal nucleation and growth rate, since many factors, including the initial crystal shape and kinetic coefficient, are unknown. In addition, it is possible that the increase in solubility with increasing carbonate is not related to the crystallite size, but rather to the change in crystal energetics. It has been shown that the solubility of hydroxylapatite powders is more closely related to the degree of atomic order of the crystallite than to the crystallite size. [83] Furthermore, the presence of a non-apatitic surface layer is expected to modulate solubility behaviors. [60] In the samples examined here, the degree of atomic order of the samples was shown to decrease with increasing carbonate substitution. The carbonateinduced change in lattice structure (XRD) and atomic ordering (Raman), and therefore the crystal energetics, was likely the most important contributor to the change in solubility. [83]

\section{Conclusions}

Through aqueous precipitation methods, biomimetic apatite nanocrystals were synthesized with carbonate concentrations from 1 to $17.8 \mathrm{wt} \%$. The carbonate was present predominantly in B-type substitution for phosphate, as found in natural bone mineral. The morphology of the crystallites was plate-like and exhibited decreasing size, aspect ratio, and faceting with increasing carbonate concentration, Fig. 8. These modifications to the morphology appear to be caused by a change in crystal energetics, including surface energies, as seen by the change in atomic order and lattice spacing with carbonate incorporation. In the range of physiological carbonate levels, 2-8 wt\% $\mathrm{CO}_{3}$, the crystallites exhibited morphologies similar to those seen in natural bone mineral. Organic (e.g., proteins, citrates) templating was not necessary for the formation of bone-like apatite nanocrystals. Instead, carbonate substitution within the physiological range was sufficient for the production of crystallites with the nano-scale size, shape, and composition under the conditions presented here. MD and DFT models of B-type substituted apatite were able to accurately predict relative changes in the lattice spacing of the crystals as well as in the compliance and theoretical surface energy of the apatites caused by carbonate incorporation. For the first time, a mechanism for how substitution controls morphology was proposed via a modified Weibull analysis. The resulting normalized size vs. carbonate concentration predictions successfully replicated the experimentally measured values. These results strongly suggest carbonation of apatites plays a critical role in controlling crystal energetics and thus the nanometer size of crystallites, which are essential to maintain proper bone mechanics and physiology. With the current focus on tissue engineering and development of biomimetic materials, this study provides a better comprehension of the processes that underlie compositional control of size and shape of 
crystalline particles. Such understanding can enable the tailoring of crystallite size at the nanometer scale by modification of composition.
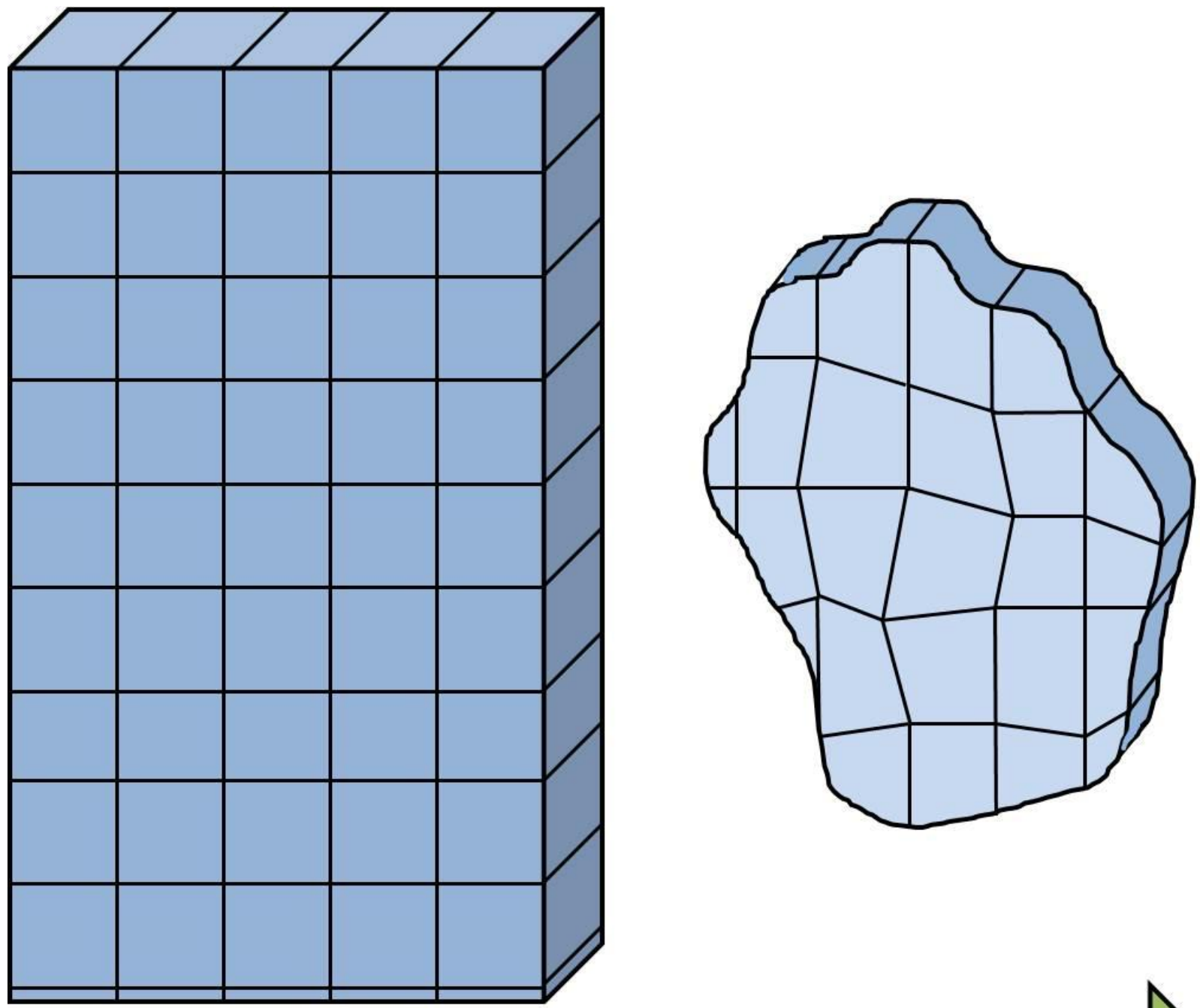

\section{$\mathrm{CO}_{3}{ }^{2-}$ and volumetric energy}

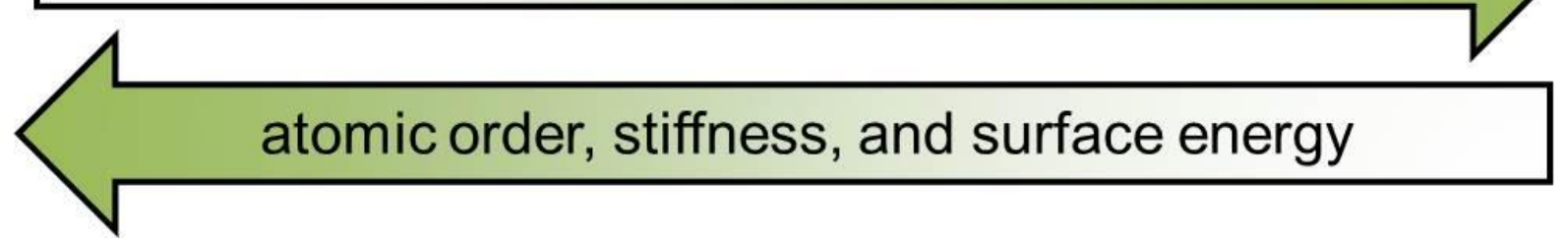

Figure 8: Schematic showing the changes in crystal morphology and energetics as a function of carbonate concentration. At low carbonate concentrations the bioapatite crystals are long faceted blades with lattice spacing close to that of geological hydroxylapatite. However, carbonate incorporation into the lattice changes the lattice parameters and decreases the atomic order, coherent domain size, and surface energy. This results in a decrease in crystal size, faceting, stiffness and aspect ratio. 
Acknowledgments:

The authors would like to acknowledge Prof. Daniel Giammar at Washington University who performed all of the ICP-MS experiments. This project was funded by the National Institute of Health (NIH) R01 EB016422 and R01 AR057836. Dr. Deymier was funded in part by the National Space Biomedical Research Institute (NSBRI) NSBRIRFA-13-01 Postdoctoral First Fellow Award. Arun Nair would like to acknowledge support from Department of Mechanical Engineering, University Arkansas. This work was supported in part by the National Science Foundation under the grants ARI\#0963249, MRI\#0959124 and EPS\#0918970, and a grant from Arkansas Science and Technology Authority, managed by Arkansas High Performance Computing Center. 
References:

[1] H.J. Gao, B.H. Ji, I.L. Jäger, E. Artz, P. Fratzl, Materials become insensitive to flaws at nanoscale: lessons from nature, PNAS 100(10) (2003) 5597-5600.

[2] D.A. Bushinsky, B.C. Lam, R. Nespeca, N.E. Sessler, M.D. Grynpas, Decreased bone carbonate content in response to metabolic, but not respiratory, acidosis, Am J Physiol 265(4 Pt 2) (1993) F530-6.

[3] C.R. Hankermeyer, K.L. Ohashi, D.C. Delaney, J. Ross, B.R. Constantz, Dissolution rates of carbonated hydroxyapatite in hydrochloric acid, Biomaterials 23(3) (2002) 743-750.

[4] K.A. Gross, C.C. Berndt, Biomedical Application of Apatites, Reviews in Mineralogy and Geochemistry 48(1) (2002) 631-672.

[5] R.C. Ropp, Encyclopedia of the alkaline earth compounds, Elsevier, Oxford UK, 2013.

[6] J. Fernandez-Moran, A. Engstrom, Electron microscopy and x-ray diffraction of bone, Biochim.

Biophys. Acta 23 (1957) 260-264.

[7] S. Weiner, H.D. Wagner, The material bone: Structure mechanical function relations, Annu. Rev.

Mater. Sci. 28 (1998) 271-298.

[8] M. Okazaki, Y. Moriwaki, T. Aoba, Y. Doi, J. Takahashi, Solubility behavior of $\mathrm{CO} 3$ apatites in relation to crystallinity, Caries Res 15(6) (1981) 477-83.

[9] S. Liao, F. Watari, G. Xu, M. Ngiam, S. Ramakrishna, C.K. Chan, Morphological effects of variant carbonates in biomimetic hydroxyapatite, Materials Letters 61(17) (2007) 3624-3628.

[10] Z. Wang, Z. Xu, W. Zhao, N. Sahai, A potential mechanism for amino acid-controlled crystal growth of hydroxyapatite, Journal of Materials Chemistry B 3(47) (2015) 9157-9167.

[11] L.-s. Gu, Y.K. Kim, Y. Liu, K. Takahashi, S. Arun, C.E. Wimmer, R. Osorio, J.-q. Ling, S.W. Looney, D.H. Pashley, F.R. Tay, Immobilization of a phosphonated analog of matrix phosphoproteins within crosslinked collagen as a templating mechanism for biomimetic mineralization, Acta Biomater. 7(1) (2011) 268-277.

[12] G. Tomoaia, R.-D. Pasca, On the Collagen Mineralization. A Review, Clujul Medical 88(1) (2015) 1522.

[13] C. Rey, C. Combes, C. Drouet, S. Cazalbou, D. Grossin, F. Brouillet, S. Sarda, Surface properties of biomimetic nanocrystalline apatites; applications in biomaterials., Progress in Crystal Growth and Characterization of Materials 60(3-4) (2014) 63-73.

[14] J.M. Delgado-López, R. Frison, A. Cervellino, J. Gómez-Morales, A. Guagliardi, N. Masciocchi, Crystal Size, Morphology, and Growth Mechanism in Bio-Inspired Apatite Nanocrystals, Advanced Functional Materials 24(8) (2014) 1090-1099.

[15] N.C. Blumenthal, F. Betts, A.S. Posner, Effect of carbonate and biological macromolecules on formation and properties of hydroxyapatite, Calcified Tissue Research 18(1) (1975) 81-90.

[16] W.J. Landis, K.J. Hodgens, J. Arena, M.J. Song, B.F. McEwen, Structural relations between collagen and mineral in bone as determined by high voltage electron microscopic tomography, Microscopy Research and Technique 33(2) (1996) 192-202.

[17] L. Chen, R. Jacquet, E. Lowder, W.J. Landis, Refinement of collagen-mineral interaction: a possible role for osteocalcin in apatite crystal nucleation, growth and development, Bone 71 (2015) 7-16.

[18] J.C. Elliott, Calcium Phosphate Biominerals, Reviews in Mineralogy and Geochemistry 48(1) (2002) 427-453.

[19] Z. Li, J.D. Pasteris, Tracing the pathway of compositional changes in bone mineral with age: preliminary study of bioapatite aging in hypermineralized dolphin's bulla, Biochim Biophys Acta 1840(7) (2014) 2331-9.

[20] S.M. Barinov, I.V. Fadeeva, D. Ferro, J.V. Rau, S.N. Cesaro, V.S. Komlev, A.S. Fomin, Stabilization of Carbonate Hydroxyapatite by Isomorphic Substitutions of Sodium for Calcium, Russ. J. Inorg. Chem. 53(2) (2008) 164-168. 
[21] D. McConnell, J.W. Gruner, The Problem of the Carbonate-apatites III Carbonate-apatite from Magnet Cove, Arkansas, The American mineralogist 25(3) (1940) 157-167.

[22] I.R. Gibson, W. Bonfield, Novel synthesis and characterization of an AB-type carbonate-substituted hydroxyapatite, J Biomed Mater Res 59(4) (2002) 697-708.

[23] R.Z. LeGeros, Calcium phosphates in oral biology and medicine, Monographs in oral science 15 (1991) 1-201.

[24] A. Bigi, G. Cojazzi, S. Panzavolta, A. Ripamonti, N. Roveri, M. Romanello, K. Noris Suarez, L. Moro, Chemical and structural characterization of the mineral phase from cortical and trabecular bone, Journal of inorganic biochemistry 68(1) (1997) 45-51.

[25] X.-F. Xiao, R.-F. Liu, Y.-J. Gao, Hydrothermal preparation of nanocarbonated hydroxyapatite crystallites, Materials Science and Technology 24(10) (2008) 1199-1203.

[26] S. Markovic, L. Veselinovic, M.J. Lukic, L. Karanovic, I. Bracko, N. Ignjatovic, D. Uskokovic, Synthetical bone-like and biological hydroxyapatites: a comparative study of crystal structure and morphology, Biomedical materials (Bristol, England) 6(4) (2011) 045005.

[27] J. Barralet, S. Best, W. Bonfield, Carbonate substitution in precipitated hydroxyapatite: An investigation into the effects of reaction temperature and bicarbonate ion concentration, J. Biomed. Mater. Res. 41(1) (1998) 79-86.

[28] J. Liao, L. Yang, J. Grashow, M.S. Sacks, Molecular orientation of collagen in intact planar connective tissues under biaxial stretch, Acta Biomater. 1 (2005) 45-54.

[29] Y. Wang, S. Von Euw, G. Laurent, C. Crevant, L. Bonhomme-Coury, M.-M. Giraud-Guille, F. Babonneau, N. Nassif, T. Azais, Impact of collagen confinement vs. ionic substitutions on the local disorder in bone and biomimetic apatites, Materials Horizons 1(2) (2014) 224-231.

[30] C.H. Yoder, J.D. Pasteris, K.A. Krol, V.L. Weidner, R.W. Schaeffer, Synthesis, structure, and solubility of carbonated barium chlor- and hydroxylapatites, Polyhedron 44(1) (2012) 143-149.

[31] P. Grøn, M. Spinelli, O. Trautz, F. Brudevold, The effect of carbonate on the solubility of hydroxylapatite, Arch. Oral Biol. 8(3) (1963) 251-263.

[32] A.C. Deymier, J.D. Almer, S.R. Stock, D.R. Haeffner, D.C. Dunand, High Energy X-ray Diffraction Measurement of Load Transfer Between Hydroxyapatite and Collagen in Bovine Dentin, in: D. Kisailus, L. Estroff, H.S. Gupta, W.J. landis, P.D. Zavattieri (Eds.), Structure-Property Relationships in Biomineralized and Biomimetic Composites, Materials Research Society, Warrendale, 2009, pp. 161-166.

[33] N.J. Flora, K.W. Hamilton, R.W. Schaeffer, C.H. Yoder, A Comparative Study of the Synthesis of Calcium, Strontium, Barium, Cadmium, and Lead Apatites in Aqueous Solution, Synthesis and Reactivity in Inorganic and Metal-Organic Chemistry 34(3) (2004) 503-521.

[34] C.H. Yoder, J.D. Pasteris, K.N. Worcester, D.V. Schermerhorn, Structural water in carbonated hydroxylapatite and fluorapatite: confirmation by solid state (2)H NMR, Calcif Tissue Int 90(1) (2012) 607.

[35] C. Yoder, J. Pasteris, K. Worcester, D. Schermerhorn, M. Sternlieb, J. Goldenberg, Z. Wilt, Dehydration and Rehydration of Carbonated Fluor- and Hydroxylapatite, Minerals (2012).

[36] B. Wopenka, A. Kent, J.D. Pasteris, Y. Yoon, S. Thomopoulos, The tendon-to-bone transition of the rotator cuff: a preliminary raman spectroscopic study documenting the gradual mineralization across the insertion in rat tissue samples, Applied spectroscopy 62(12) (2008) 1285-1294.

[37] A.G. Schwartz, J.H. Lipner, J.D. Pasteris, G.M. Genin, S. Thomopoulos, Muscle loading is necessary for the formation of a functional tendon enthesis, Bone 55(1) (2013) 44-51.

[38] A.G. Schwartz, J.D. Pasteris, G.M. Genin, T.L. Daulton, S. Thomopoulos, Mineral distributions at the developing tendon enthesis, PLoS One 7(11) (2012) 9.

[39] G.M. Genin, A. Kent, V. Birman, B. Wopenka, J.D. Pasteris, P.J. Marquez, S. Thomopoulos, Functional grading of mineral and collagen in the attachment of tendon to bone, Biophys J 97(4) (2009) 976-85. 
[40] A. Grunenwald, C. Keyser, A.-M. Sautereau, E. Crubezy, B. Ludes, C. Drouet, Revisiting carbonate quantification in apatite (bio)minerals: a validated FTIR methodology, Journal of Archaeological Science 49 (2014) 134-141.

[41] Standard Methods for the Examination of Water and Wastewater, American Public Health Association, American Water Works Association, Water Environment Federation, Washington, DC, 1999. [42] D. Mkhonto, N.H. de Leeuw, A computer modelling study of the effect of water on the surface structure and morphology of fluorapatite: introducing a Ca10(PO4)6F2 potential model, J. Mater. Chem 12 (2002) 2633-2642.

[43] N.H. De Leeuw, A computer modelling study of the uptake and segregation of fluoride ions at the hydrated hydroxyapatite (0001) surface: introducing a $\mathrm{Ca} 10(\mathrm{PO}) 6(\mathrm{OH}) 2$ potential model, Phys. Chem. Chem. Phys. 6 (2004) 1860.

[44] R. Astala, M.J. Stott, First Principles Investigation of Mineral Component of Bone: CO3 Substitutions in Hydroxyapatite, Chem. Mat. 17(16) (2005) 4125-4133.

[45] E. Menendez-Proupin, S. Cervantes-Rodriguez, R. Osorio-Pulgar, M. Franco-Cisterna, H. CamachoMontes, M.E. Fuentes, Computer simulation of elastic constants of hydroxyapatite and fluorapatite, J Mech Behav Biomed Mater 4(7) (2011) 1011-20.

[46] J.A.L. Rabone, N.H. de Leeuw, Potential routes to carbon inclusion in apatite minerals: a DFT study, Phys Chem Minerals 34(7) (2007) 495-506.

[47] S. Peroos, Z. Du, N.H. de Leeuw, A computer modelling study of the uptake, structure and distribution of carbonate defects in hydroxy-apatite, Biomaterials 27(9) (2006) 2150-61.

[48] S. Plimpton, Fast Parallel Algorithms for Short-Range Molecular Dynamics, Journal of Computational Physics 117(1) (1995) 1-19.

[49] W.Y. Ching, P. Rulis, A. Misra, Ab initio elastic properties and tensile strength of crystalline hydroxyapatite, Acta Biomater. 5(8) (2009) 3067-3075.

[50] J.M. Hughes, M. Cameron, K.D. Crowley, Structural variations in natural F, $\mathrm{OH}$, and $\mathrm{Cl}$ apatites, American Mineralogist 74(7-8) (1989) 870-876.

[51] R. Astala, M. Stott, First-principles study of hydroxyapatite surfaces and water adsorption., Phys. Rev. B 78 (2008) 1-11.

[52] W. Humphrey, A. Dalke, K. Schulten, VMD: visual molecular dynamics, J. Mol. Graph 14 (1996) 33-8, 27-8.

[53] D. Vanderbilt, Soft self-consistent pseudopotentials in a generalized eigenvalue formalism, Physical review. B, Condensed matter 41(11) (1990) 7892-7895.

[54] L. Fast, J.M. Wills, B. Johansson, O. Eriksson, Elastic constants of hexagonal transition metals: Theory, Physical review. B, Condensed matter 51(24) (1995) 17431-17438.

[55] W. Weibull, A statistical distribution function of wide applicability, J. Appl. Mech. 73 (1951) 293.

[56] D. Askeland, P. Fulay, W. Wright, The Science and Engineering of Materials Cenage Learning, Independance, KY, 2010.

[57] A.M. Freudenthal, Statistical approach to brittle fracture, s.n.], S.I., 1968.

[58] X. Gao, C. Ruggieri, R.H. Dodds, Calibration of Weibull stress parameters using fracture toughness data, Int. J. Fract. 92(2) 175-200.

[59] G. Montel, G. Bonel, J.C. Heughebaert, J.C. Trombe, C. Rey, New concepts in the composition, crystallization and growth of the mineral component of calcified tissues, Journal of Crystal Growth 53(1) (1981) 74-99.

[60] C. Rey, C. Combes, C. Drouet, D. Grossin, Bioactive Ceramics: Physical Chemistry, in: P. Ducheyne, K.E. Healy, D.W. Hutmacher, D.W. Grainger, C.J. Kirkpatrick (Eds.), Comprehensive Biomaterials, Elsevier2011, pp. 187-221.

[61] R.S. Gilmore, J.L. Katz, Elastic properties of apatites, J. Mater. Sci. 17(4) (1982) 1131-1141. 
[62] J.L. Katz, K. Ukraincik, On the anisotropic elastic properties of hydroxyapatite, J. Biomech. 4(3) (1971) 221-227.

[63] R.Z. LeGeros, O.R. Trautz, J.P. Legeros, E. Klein, W.P. Shirra, Apatite crystallites: effects of carbonate on morphology, Science 155(3768) (1967) 1409-11.

[64] C. Drouet, Apatite Formation: Why It May Not Work as Planned, and How to Conclusively Identify Apatite Compounds, BioMed Research International 2013 (2013) 12.

[65] C. Rey, B. Collins, T. Goehl, I.R. Dickson, M.J. Glimcher, The carbonate environment in bone mineral: a resolution-enhanced Fourier Transform Infrared Spectroscopy Study, Calcif Tissue Int 45(3) (1989) 15764.

[66] Y. Suetsugu, Y. Takahashi, F.P. Okamura, J. Tanaka, Structure Analysis of A-Type Carbonate Apatite by a Single-Crystal X-Ray Diffraction Method, Journal of Solid State Chemistry 155(2) (2000) 292-297.

[67] R.Z. LeGeros, O.R. Trautz, E. Klein, J.P. LeGeros, Two types of carbonate substitution in the apatite structure, Experientia 25(1) (1969) 5-7.

[68] Y. Pan, M.E. Fleet, Compositions of the Apatite-Group Minerals: Substitution Mechanisms and Controlling Factors, Reviews in Mineralogy and Geochemistry 48(1) (2002) 13-49.

[69] B. Wopenka, J.D. Pasteris, A mineralogical perspective on the apatite in bone, Materials Science and Engineering: C 25(2) (2005) 131-143.

[70] J.A.M. Zahedi, F. Ziaie, M.M. Larijani, S.M. Borghei, A. Kamaliyanfar, Synthesis and Characterization of Sodium-carbon Apatite Nano-crystals by Chemical Sedimentation Method, Indian Journal of Science and Technology 5(3) (2012) 2464-2467.

[71] I.C. Noyan, J.B. Cohen, Residual Stress: Measurement by Diffraction and Interpretation, SpringerVerlag, New York, 1956.

[72] V. Ziv, S. Weiner, Bone Crystal Sizes: A Comparison of Transmission Electron Microscopic and X-Ray Diffraction Line Width Broadening Techniques, Connect. Tissue Res. 30(3) (1994) 165-175.

[73] J.P.R.O. Orgel, A. Miller, T.C. Irving, R.F. Fischetti, A.P. Hammersley, T.J. Wess, The in situ supermolecular structure of type I collagen, Structure 9 (2001) 1061-1069.

[74] E.J. Miller, S. Gay, W.C. Leon, [1] The collagens: An overview and update, Methods in Enzymology, Academic Press1987, pp. 3-41.

[75] W.J. Landis, M.J. Song, A. Leith, L. McEwen, B.F. McEwen, Mineral and organic matrix interaction in normally calcifying tendon visualized in three dimensions by high-voltage electron microscopic tomography and graphic image reconstruction, J Struct Biol 110(1) (1993) 39-54.

[76] M.J. Glimcher, Recent studies of the mineral phase in bone and its possible linkage to the organic matrix by protein-bound phosphate bonds, Philosophical transactions of the Royal Society of London. Series B, Biological sciences 304(1121) (1984) 479-508.

[77] F. Nudelman, K. Pieterse, A. George, P.H.H. Bomans, H. Friedrich, L.J. Brylka, P.A.J. Hilbers, G. de With, N.A.J.M. Sommerdijk, The role of collagen in bone apatite formation in the presence of hydroxyapatite nucleation inhibitors, Nat Mater 9(12) (2010) 1004-1009.

[78] A. George, A. Veis, Phosphorylated proteins and control over apatite nucleation, crystal growth, and inhibition, Chemical reviews 108(11) (2008) 4670-93.

[79] A.C. Deymier-Black, J.D. Almer, S.R. Stock, D.R. Haeffner, D.C. Dunand, Synchrotron X-ray diffraction study of load partitioning during elastic deformation of bovine dentin, Acta Biomater. 6(6) (2010) 21722180.

[80] J.B. Forien, C. Fleck, C. Krywka, E. Zolotoyabko, P. Zaslansky, In situ compressibility of carbonated hydroxyapatite in tooth dentine measured under hydrostatic pressure by high energy X-ray diffraction, J Mech Behav Biomed Mater 50 (2015) 171-9.

[81] B. Mutaftschiev, The atomistic nature of crystal growth, Springer Science \& Business Media 2013.

[82] R.B. Abernethy, The New Weibull Handbook, Robert B. Abernethy, North Palm Beach, Florida, 2004. 
[83] A.A. Baig, J.L. Fox, R.A. Young, Z. Wang, J. Hsu, W.I. Higuchi, A. Chhettry, H. Zhuang, M. Otsuka, Relationships among carbonated apatite solubility, crystallite size, and microstrain parameters, Calcif Tissue Int 64(5) (1999) 437-49. 